\title{
Universal History and the Emergence of Species Being ${ }^{1}$
}

\author{
Haines Brown \\ Central Connecticut State University, Emeritus \\ Haines@histomat .net
}

2016.11.09

1. Copyright owned by author. 


\begin{abstract}
This paper seeks to recover the function of universal history, which was to place particulars into relation with universals. By the $20^{\text {th }}$ century universal history was largely discredited because of an idealism that served to lend epistemic coherence to the overwhelming complexity arising from universal history's comprehensive scope. Idealism also attempted to account for history's being "open"- - for the human ability to transcend circumstance. The paper attempts to recover these virtues without the idealism by defining universal history not by its scope but rather as a scientific method that provides an understanding of any kind of historical process, be it physical, biological or human. While this method is not new, it is in need of a development that offers a more robust historiography and warrant as a liberating historical consciousness. The first section constructs an ontology of process by defining matter as ontic probabilities rather than as closed entities. This is lent warrant in the next section through an appeal to contemporary physical science. The resulting conceptual frame and method is applied to the physical domain of existents, to the biological domain of social being and finally to the human domain of species being. It is then used to account for the emergence of human history's initial stage - the Archaic Socio-Economic Formation and for history' stadial trajectory-its alternation of evolution and revolution.
\end{abstract}

Keywords - universal history, species being, emergence, historical materialism, socio-economic formation, post-humanism, Marxism, ontic probability 


\section{Introduction}

Its objective idealism is why traditional universal history lost credibility; today, it must instead be scientific and materialist. The aim will be to elaborate the method that supports this more scientific kind of historiography. It is here named a constructive abstraction because this term is least presumptive and because the method enlarges upon observed phenomena by engaging unobservables.

The word "universal" conventionally refers to what is true at all times and places. However, any such claim is inherently idealist. So it will here instead refer to a method that conveys an understanding of any kind of historical process, be it physical, biological or human. Argued will be that this necessarily makes universal history materialist rather than idealist, and that as a consequence explanatory success appeals to constructive action rather than intelligibility (Munshi 1978). This is unconventional enough to require idealist history first be defined to serve as its counter.

An example of traditional idealist universal history is Bishop Bossuet's Discours sur l'histoire universelle (1681). In a fundamental way it defines the shape of universal history in the modern West. Bossuet's explicit aim was to see if it is possible to construct a comprehensive history that conveys the meaning of the particular facts found in all sources, both profane and sacred, in relation to the universal divine plan. The problem was that by his time comprehensiveness had come to engage a much larger and more complex world lacking in parochial coherence. This forced him to shift the source of the world's coherence from an objective divine plan to the observer's subjective perspective. He argued that progress in the "arts of subsistence" (Bossuet 2010, 4-6) now empowered the individual to adopt what we would call the anthropocentric humanist position that an explanation of the past is its meaning for a present individual observer (Bossuet 2010, vi-vii). Thus historiography becomes a cognitive construct that subsumes the data of experience.

In sociological terms the development of private property had come to support a socially constructed potency of "ownership" rather than a divinely ordained natural use right (Tierney 2006). It empowered the individual to be the autonomous measure of the world. This Western ethos is manifest in the adoption of perspectivism in the fine arts (Maiorino 1976) and in Galileo's reduction of the world to mathematics (Moran 2012, Chapter 3). The present paper will replace this humanistic anthropocentrism with a posthumanist materialism in which mankind is seen as the most improbable actualization of natural possibilities rather than independent of material determination.

To warrant humankind's appropriation of the divinely plan, the mind was reified and lent ontological priority over matter. Because of this Cartesianism, historical development appeared to emerge from a rational weighing of opportunities by the owners of property rather than being the result of an effort to actualize the world's possibilities: the coherence of the past emerges as the outcome of rational choices made by competing empowered individuals (Kant 1963, 14-16 et passim).

The world is conventionally known through its causal effects on sensory organs or measurement instrumentation. As the result, the relation of things is viewed as causal. The world's furniture appears to stand in unequivocally deterministic relations. This makes the world seem rationally coherent and predictable. However, causality is an artifact of reduction (Norton 2003). The world in fact consists of processes that are always open and thus not entirely predictable (Duara 1998). A

Cartesian primacy of mind not only reduces the world to phenomena, but also frees the mind to invent private understandings and explanations. This humanism lent universal history its characteristically speculative character (as in Schiller 1972). 
Nineteenth-century positivists objected to this unscientific subsumption of fact under ideas. However, change, as important as it was in the Western ethos, was unintelligible without an objective idealism to serve as a fulcrum for a transcendence of existents. So they continued to attribute causal potency to ideal cognitive constructs such as the rational totalities of cultures, civilizations and societies, which lent warrant to their comparative method (Ghosh 1964). The reduction also required the construction of irreducible "base elements" that supported a methodological individualism suited to a world of closed entities. As the result, universal history gave way to a "world history" arising from the interaction of closed units inferred from observables (Dirlik 2005). This put history in thrall to existents, to the past, rather than viewed as an emergent process open to the future. The price paid for ridding universal history of its idealism was that historic consciousness ceased being, as Lord Acton is supposed to have claimed, the keystone of liberty, a method by which to transcend circumstance (Aufhebung).

Universal historiography is nevertheless worth salvaging. The reasons are conventional enough. Put simply, local history cannot be adequately understood independently of the wider world; only an open historiography that engages real possibilities can make historic consciousness liberating; given today's global integration it is necessary to understand the relation of differences in positive rather than in just the antagonistic terms implied by the causal relation of closed entities.

This salvage effort requires an ontological monism, for universality is incompatible with an objective idealism that cleaves the world into incommensurate ontic domains. Because biological and mental life initially arose from matter, one cannot argue they are ontologically independent of it. However, to accommodate them, it will be argued that the concept "matter" must be redefined to refer to ontic probabilities. Philosophers may be inclined to appeal instead to ideal modal possibilities, but the paper's prioritization of action means it must look to science rather than to philosophy. It will jettison idealism by reconciling possibility and actuality as merely aspects of one ontological category, that of ontic probability.

Historiography must recover an understanding of open processes rather than presume a causal relation of a reified past and the present (Fillion 2014). Scientificity means reaching beyond immediate impressions and subjective meaning to discover how processes actually work. It will be argued therefore that universal history must employ a universal method rather than pursue a quixotic universal representation. Being universal, the method should provide an understanding of any process that is "historical" in the sense that it is the actualization of ontic probabilities.

The price will be a restraint on explanation. A universal historiography engages the physical, biological and human domains distinguished by behaviors that in principle cannot be explained in terms of the domain from which they emerged. Life, for example, is a behavior entirely unknown in the physical domain. As the result, an account of the emergence of a new domain is limited to a description of the possibilities for it in a prior domain rather than any necessity for it. This is not sufficient for explanation (Reiner 1993). However, if action rather than cognition is primary, the novelty of new domains is adequately addressed in material rather than logical terms.

To make processes intelligible, a painful discussion of ontology is unavoidable. The next section will argue that historical explanation does not reduce to empirical statements of fact about phenomena (in the case of natural science, see, for example A. Cross 1991). Historical processes never reduce entirely to existents, but are always to some extent improbable in reference to them. Argued will be that the warrant for explanation is not so much cognitive mastery, heuristics or a ground for further investigation, but its support for constructive action in the world (Nyrup 2015). 


\section{An Ontological Break with Folk Science}

Before trying to explain the emergence of the physical, biological and human domains, it is necessary to construct with the aid of contemporary physical science a conceptual framework and ontology adequate for an understanding (support for effective action in natural world) and explanation (support for effective action in social world) of processes. Unfortunately this means stepping out of the comfortable world familiar to us in daily life.

\subsection{The effect of cognitive closure}

We enter here upon choppy waters. Mal de mer is reduced by distinguishing contemporary science from the folk science associated with folk psychology (Churchland 1989; Gelman and Legare 2011). Folk psychology can be understood as a biological adaptation for an organism to act upon sensory information in order to predict outcomes in support of homeostasis- the reproduction of its life. While undoubtedly useful, this can be problematic because, as we know today, the data of experience are a function of the observer's nature and, with a centralized neural system, the observer's a priori conceptions (Jantzen, Mayo, and Patton 2015). The egocentric perspective of folk psychology thus encourages solipsism and imposes a mereology that encloses the self and reduces what is other to its effects on the self.

Adaptation and innovative action are fundamentally different ways to engage the world. Prediction in support of adaptation is possible to the degree the world is engaged as a determinant state of affairs inferred from phenomena that can be represented in thought. While the resulting cognitive construct is a useful tool in a deterministic world, it cannot represent emergent processes that, it will be argued, can only be engaged through action.

Since prediction is enhanced by a narrowing of scope, traditional European science represented the world in terms of a point-set typology. At points in an ideal Cartesian space exist sets of intrinsic properties that exhaustively define an deal entity located there. So the outcome of the interaction of entities is unequivocally determined by their intrinsic properties. This defines a world driven by unequivocal necessity, is fundamentally logical and is accessible to rational thought. Because nothing exists beyond a point except other points, the entity becomes the fundamental unit of analysis (Wilson 2012; Butterfield 2006). This reduction to intrinsic properties lends the entity autonomy and enables it to truck and barter freely with other entities.

However, if things are processes they cannot be defined solely in terms of intrinsic properties. So to reconcile change with essential being, folk science distinguishes persistent properties and evanescent properties on the basis of a subjective and arbitrary measure of time. The former are lent the status of being essential in contrast to ephemeral accidentals that do not support explanation because they fail to support prediction. This infers ontology from epistemology and reduces processes to a sequence of static states (Dieks 2006).

Because of its closure for the sake of intelligibility, the method of early modern European science represents a "reductive abstraction." It reduces what is significant to what happens to persist longer, is spatio-temporally local and thus observable, and acquires meaning through its relation to ideal totalities or laws. That is, essential properties standing in predictable and thus necessary relations form persistent sets that are reified to make an independent difference in the world (Pitkin 1987). While the method of reductive abstraction is practical in daily life, it gives rise to a host of problems when not in service to an open conception of the world. 
One problem faced by the method of reductive abstraction is that while it supports useful prediction, it makes historical processes unintelligible. We experience a process and know it to be one, but are unable to subject it to reason or convey it through the language of daily life. Saint Augustine made this point in relation to time (Confessions, 11.14.17). Neuroscience shows why: in order for the brain to subject phenomenal information to cognitive processing, the analog inputs from sensory organs are temporally segmented into digital action potentials (Kurby and Zacks 2008; Field and Hineline 2008). Instead of seeing historical processes as a dialectic of possibility and necessity in the present, the mind reifies the "past" as an ideal causal determinant of the present despite its not existing in the present.

The method of reductive abstraction also introduces an "epistemological gap" between what is spatio-temporally local and what is not, between observables and what is not observable, between the self as observer and the observed other and between a phenomenon and Ding an sich. This makes it impossible to warrant statements of fact without already knowing the nature of their referents (Chalmers 2006). To the extent scientific realism is defined in terms of the truth value of statements about theoretical entities, it suffers from the same problem (Sterpetti 2015). This paper aims to close the epistemological gap by taking action to be fundamental rather than presume a dichotomy of cognizing entity and observables, for in action agent and object become merely aspects of a single process.

Yet another difficulty is that there is no reason in folk science to assume that a spatial widening of the frame to include other entities will remain coherent and thus intelligible unless everything is viewed an artifact of ideal universals. This is why the force of universal laws is occult (Bigelow, Ellis, and Pargetter 1988); why laws do not correspond with reality (Cartwright 1983).

Finally, it encourages a representation of the world in terms of systems. Although widely taken for granted, a systems view is an artifact of unwarranted idealist reifications. A system effect emerges from simply the causal relation of its constituents (Ladyman and Ross 2007, 3-4, 5357). These constituents are taken to be closed observables that are essentially independent of the observer or other entities. Base elements by definition are self-contained and not reducible; they are a priori. A systems approach nicely supports prediction, but not constructive action. However this essentially conservative function is not generally recognized.

However necessary folk psychology is for biological survival and useful in daily life, it offers neither an understanding nor an explanation of historical processes that transcend circumstances rather than be unequivocally determined by them. The aim is now to construct an alternative ontology that supports an understanding of historical processes in terms of contemporary science.

\subsection{An ontological break}

In physical science all things are processes that occur in a time that ranges from near Planck time to cosmic time. Even cosmic heat death will not end change absolutely. This universality of processes implies that things have an inherent tendency to change rather than change being an artifact of causality. That is, if persistence is never absolute, then change is universal.

The only way to understand matter as a process is to define it right from the start as ontic probabilities rather than as tangible entities. An ontic probability is an objective propensity for change that references actualities (as tangible observables will here be called). No doubt defining matter as dispositions is at odds with folk psychology and common sense, but it will be argued is entirely compatible with contemporary natural science. 
Lest there be confusion, ontic probabilities are not epistemic probabilities. The latter are "frequentist" in that the probability distribution of past outcomes is calculated after the fact of multiple runs (Hacking 2001, 189-200). An ontic probability is instead a real single-case propensity for change in the present (Gillies 2000). Its classic discussion is that of Karl Popper (Popper 1959; for a review of the literature, see T. Cross 2012).

A problem is that if all matter is inherently in motion, then the concept of transcendence becomes orphaned, for there is nothing stable to transcend. In the West transcendence often relies on the presence of an ideal reification that enables actual matter to be transcendent because what is ideal is not actual. Here instead motion will not refer to empirical change but to a change in the value of a "structure." Structure might be understood as both extrinsic (probability value becoming maximally probable in reference to its circumstances) and intrinsic (probability values becoming maximally probable in reference to each other), but there they are the same. This maximal probability serves to define observable "actualities." So a change refers to a new set of probability values becoming maximally probable in place of an old.

When not actual, an ontic probability is unobservable and thus is theoretical. While practicing scientists generally accept the reality of theoretical entities (Boyd 1991), this "scientific realism" is usually understood in epistemological terms as a belief that a theoretical concept can be true in reference to the world. To avoid this epistemological gap appeal is now usually made to the "nomiracles argument" that unobservables are real because they make an observable difference. This cannot mean that the only real probabilities are those that have observable effects, for they are the condition of change itself, not just its outcomes. Here theory will refer to ontic probabilities that don't happen to be actual but are nevertheless real. This is familiar enough in quantum mechanics (for example see Bell 2004).

The data of observation are constructed by sensory organs in accord with their powers and are made intelligible by a priori conceptions and categories (Robus 2015). As the result, observability is a poor indicator of what is real. This paper avoids the problem by defining matter as an ontic probability distribution that has both an observable (maximally probable) and an unobservable (non-local) aspect. Matter thus defined exhausts the physical, biological and human domains that emerged with the Big Bang from the perfect vacuum of virtual probabilities; all reality ultimately originated from virtual probabilities. There is nothing supernatural over and above matter when so defined. While the behaviors that distinguish these three domains must have been possible in the vacuum, they are not caused by it. But in a probabilistic world, what is possible must eventually become actual if circumstances allow.

Understanding a world that engages non-actual ontic probabilities calls for a method that Bertell Ollman called a "constructive abstraction" (Ollman 2003, chapter 5). That is, a conception of the world must be constructed from theoretical entities as well as observables. The term "historical materialism" for this method is more appealing, but it would be presumptuous to use it in this context. The point to be argued is that the method is based on action informed by theory rather than simply wedding theoretical entities with observables. Contrary to Ollman's defining ontic probability as the propensity for something to cause an event, in the next section this relation will be reversed. It will be action, a change in probability value, that constructs actualities; action is a priori to actualities.

Someone might well ask how is it possible to base science on unobservable probabilities? It will be argued that the method of constructive abstraction discovers unobservable ontic probabilities through action, for they are indexed by the effort needed to produce a change rather than 
inferred from its outcome. It thus differs from a reductive abstraction that passively culls phenomenal effects in order to construct ideal categories. However, it is not suggested that constructive abstraction replace reductive abstraction, for the two methods are interdependent. To be real rather than virtual, probabilities must reference actualities. Which method is emphasized depends on the degree to which the goal is adaptation or transcendence, whether the object of study is relatively closed or open. However, both must always be present.

In short, "matter" will here refer to ontic probability distributions. While non-actual probabilities are undetectable except through action, it will be argued that probabilities that happen to be maximally probable in relation to circumstance constitute spatio-temporally delimited observable structures. So actualities are the being of a process, while non-actual probabilities are its becoming (Humphreys 2004). Of course ontic probabilities are not universal in the sense of being everywhere at all times, but rather in the sense of constituting all matter. Argued will be that non-actual probabilities simply lack the properties of space and time.

If explanation takes non-local unobservables into account, it runs counter to a historiographic canon that explanation be framed as a common-sense narrative based on observables (Velleman 2003). Narrative is appealing because it accords with the short-range experience of daily life and also because a reification of the past as a determinant of the present can provide individual identity as an empowered agent. So why should common sense submit to a scientific understanding of processes? The justification for doing so is that it informs innovative action not in thrall to the past.

\subsection{Implications of the break}

The method of constructive abstraction represents an "ontological break" that redefines a priori assumptions to accord with constructive action rather than intelligibility. The paper thus distances itself on one hand from a reification of structures not anchored by actualities and on the other from a radical empiricism.

This break has implications quite alien to folk science. For example, every beginning physics student quickly learns that lab experiments do not turn out as the textbook predicts and so must learn about standard deviation. This is a mathematical reductive abstraction that discounts the significance of actual outcomes and instead bases prediction on the ideal construct of their Gaussian mean. While this does support prediction, the reason for deviations in the actual outcomes in the real world is ignored (Brzechczyn 2009). If these actual outcomes are subsumed under the Gaussian mean, probabilities bifurcate into accurate description and ideal meaning.

If despite common sense ontic probabilities are taken to be fundamental, then the terms actuality and possibility refer to an extensive property known as their "value." The value of a probability conventionally falls somewhere between absolute certainty (a value of one) and absolute impossibility (a value of zero). However both are only hypotheticals, for in the natural world nothing is absolutely certain or impossible, and actual processes always fall between the two. So a probability's value is a measure of the propensity under the circumstances for a non-local probability value to become actual and acquire spatio-temporal locality. Probability values are extrinsic in that they are relative to actualities and simply refer to the value in a probability distribution that happens to be maximally probable under the circumstances. Properties corresponding to this maximal probability are thus neither intrinsic nor an ideal essence.

Non-actual probabilities will be characterized as "accessible" if their value references what is 
maximally probable in their distribution. It is their propensity for becoming maximally probable and thus actual under the circumstances rather than for becoming other. This is contrary to common sense and is admittedly challenging, in part because some aspects have yet to be explained.

"Actualization" will refer to that aspect of action in which an ontic probability value is becoming maximally probable, actual and spatio-temporally local. In folk science, actualities are defined as observable isolates and so change can only refer to an observable acquiring a new empirical state rather than as a new probability value that has become maximally probable in relation to its world. Change here refers to probability values, not to empirical properties.

The reader might suspect that the argument has been logically incoherent because both ontic probabilities and action were taken to be fundamental. However, this is not the case because the improbability of non-actual probabilities is not here taken to be an engine of change but only a measure of how much change can occur. The term "action potential" will here be the measure of possible change rather than refer to a cause. The next section argues that action takes place when a propensity to become more probable balances a propensity to become less probable, and circumstances allow them to be actual.

To anchor this admittedly abstruse discussion, attention now turns to the physical domain. Each "domain"- - here assumed to be the physical, biological and that of humankind-will be distinguished by a behavior that was inaccessible in the domain from which it emerged. The physical domain is characterized by physical existence. The existence of actualities gives ontic probabilities value and thus a propensity for actual existence. Out of cowardice the logical circularity of action creating its own necessary conditions will not be addressed in regard to the physical domain, but it will be for the two other domains.

\section{The Behavior of the Physical Domain}

The perfect vacuum from which physical existents emerged with a Big Bang lacked the actualities necessary for probabilities to reference and thus acquire value. As the result, probabilities in the vacuum were only virtual and unable to make physical existence accessible. This makes the appearance of physical existence difficult to explain.

However, it can be described in mathematical terms as a "symmetry break" (Anderson 1972). There are two kinds of symmetry break. The kind that accounts for the three cosmic domains and thus the actualization of improbabilities that are "radical" because independent of persistent existents is called a "spontaneous symmetry break" (as in Smeenk 2006). The word spontaneous will here emphasize that access to radically improbable behavior is discovered through the action characteristic of a new domain rather than necessitated by the old. The other kind of symmetry break is an "explicit symmetry break," which is more readily understood and is always taking place. It is the actualization of ontic probabilities that are accessible because they reference existing actualities.

The Higgs mechanism by which the actual existence of physical mass spontaneously emerged will not be discussed here, and physical existence will simply be taken for granted. Attention turns instead to the mechanism of the explicit symmetry breaks by which novel properties appear within the physical domain. Explanation begins with the concept of grounding. 


\subsection{Grounding}

The value of an ontic probability is extrinsic in that it depends on the value of actualities. The likelihood of rain today depends on meteorological conditions and is not merely an epistemological artifact. This determination of an ontic probability's value by actual existents will be referred to as "grounding." This term has become the standard way to refer to a non-causal dependence (in general, see Audi 2012; Clark and Liggins 2012). Grounding is typically defined as one entity acquiring a property by virtue of another. However, this should not carry any implication that actualities "cause" probability values, for propensity in itself is not action.

It is generally taken for granted that an actuality grounds because it is a particular (Hörz et al. 1980, 106), here understood to be because it is the specific "maximal probability value" defined by proximate grounds (ignored is action at a distance where space and time remain unfolded. For speculation concerning this, see [Maldacena 2016]). This makes its properties spatio-temporally local and unambivalent. What is not maximally probable and particular offers only a fuzzy ground.

Assumed is that there are distributions of ontic probability values, that each distribution has an a value that happens to be maximally probable under the circumstances and is its actual value and this actuality grounds all probability values in the distribution. So a probability distribution is a set of probability values that have a propensity to acquire the same value as its actual value.

If circumstantial actualities were to be ignored, the propensity of an actuality would simply be to actualize its own value, its structure in hypothetical isolation. This value will be referred to as its "self-ground," its ground of being. However, probabilities never in fact exist in isolation and so are grounded as well by other actualities. Because no two actualities can be absolutely identical (the Pauli Exclusion Principle), these exogenous grounds give the distribution a new value so that it becomes a distribution of vectors. It becomes a set of various propensities for probabilities that qualitatively differ from the actuality to become maximally probable.

The net weight of the exogenous grounds and self-grounding establishes a distribution's maximal probability value and thus the actuality's actual value. As the result the actuality acquires two propensities. On one hand an actuality tends to move toward the persistent value of itself in hypothetical isolation. On the other it tends to move toward the net probability defined by its exogenous grounds, toward becoming what is other than self. So an actuality's value is both being and becoming. It is process because other exogenous grounds keep it from actualizing its self-ground, while its self-ground keeps it from being merely an artifact of circumstance.

Because the distribution's accessible states references an actuality's actual value, an emergent actuality remains "true to itself" in the sense that its ground establishes the likelihood of qualitatively different probabilities in the distribution to become actual. That is, an actuality is not a persistent structure based on a probable relation of essential properties or base elements, but is inherently becoming other than self because of the grounding of circumstance. All matter is thus in motion (a classic discussion is that of Engels 1940).

The physical mechanism of actualization is an unfolding (borrowing a term from string theory) of the dimensions of space and time (Brown 2014; Balasubramanian 2011). Because two actualities cannot occupy the same state space, in folk science actualities acquire separation as spatially local particulars. Another challenge is that an actuality's becoming cannot be the same value as that of its being, and so it unfolds the dimension of temporality to separate them. The result is that particularity gives rise to local time asymmetry despite the symmetry of physical laws (Loew 2016). Admittedly this is speculative, although it does resolve an array of problems. 
The unfolding of spatial and temporal specificity will be referred to as "localization," the becoming of a unique particular that is maximally probable in reference to its endogenous and exogenous grounds. Localization enables actualities to ground measurement instrumentation and sensory organs, and so they are called "observables" (Kosso 1988). Because spatiality is a condition for existence as a unique particular, grounding acquires the property of relative weight that is a function of proximity. The greater is the proximity, the weightier is its ground.

In short, being and becoming are due to the different sources of grounding, which give rise to opposite propensities. One propensity is for an actuality to move toward a more probable relation with its self-ground and the other propensity is to move toward a more probable relation with actualities other than itself (for example, Konopka, Markopoulou, and Severini 2008). The former is to become more probable and the latter to become less probable in reference to the actuality's present or existent value. This offers a definition of "process." While it might seem to clash wildly with folk science, it in fact merely enlarges upon it.

\subsection{The primacy of action}

The Big Bang constructed existents from virtual probabilities, and so the action of becoming is primary; actuality, local being, existence and identity is secondary (Dorato 2006). Given this, a mere description of observables in isolation makes being and becoming logically contradictory: it defines being as the effect of the "past," reified so as to acquire causal efficacy in the present; a reified becoming is attributed to a future of ideal possibilities that enable innovative action in the present. Clearly processes cannot be understood in folk terms.

Here instead the "past" simply refers to an actuality's self-ground that slows its rate of becoming. The open "future" will here refer to presently accessible but unactualized probability values that reference what is actual (Capek 1981). The past and future are thus merely aspects of a process that, as will be seen, constructs its own time and space.

When a probability value more probable than an actuality is actualized, it is conventionally known as "dissipation." Here it means that a non-actual probability more probable than the existing actuality is becoming become maximally probable. If a value less probable than an actuality is becoming actual and thus maximally probable in reference to existents, it will here serve to define "emergence."

There are two kinds of emergence (Bedau and Humphreys 2008). What is known as weak emergence is a description of novel properties that predictably arise from a causal interaction of actualities. The observed correlation of base and emergent actualities is generalized to support prediction. A strong emergence on the other hand refers to novel properties that can not be predicted from knowledge of the base actualities although dependent on them.

Because these concepts are epistemological, different ones will be used. A weak emergence will be called a "regular emergence" to indicate that novelties will not be viewed as resulting from a causal relation of existent actualities but as the actualization of accessible probability values that existent grounds make maximally probable. It is called regular because the probability value of emergents is determined by existents-by the folk notion of "past." Strong emergence on the other hand will be called a "radical emergence" because it is independent of existents and is grounded instead by artifacts of present action. This kind of emergence will be dealt with at a later point.

Folk science sees dissipation as the engine of emergence because memory allows a comparison of past and present observable states. The future is unobservable and so, without an appeal to ideal 
forces, emergence lacks explanation. In folk science the actuality having a relatively weightier self-ground is assigned the function of the "agent," and the one with the lesser self-ground has the function of "object." In this paper these are viewed as one-sided reifications of a process.

Regular emergence actualizes those accessible probability values that are least improbable. However, if a new ground comes into play, it alters a probability distribution so that what is now actualized becomes in part a function of the new ground. Now, this is admittedly a gross simplification, for in fact actualities are complexities with a host of properties. So a new ground's effect on what is actualized is highly variable and depends on the specific weights and qualities of all grounds. However, the aim here is not to explain particular situations, but a method.

Bringing in unobservable ontic probabilities to support explanation does not invite empty speculation, for it will be shown that non-actual probability values are subject to "discovery." A change in probability value in one direction must balance an equal and opposite change of value in the opposite direction, and the value of non-actual probabilities are discovered through the observable dissipation that balances their actualization.

An example is obviously needed. Of much interest in robotics is the relation of the haptic sense of touch coupled with muscular effort. The propensity of a rubber ball for being squeezed, its probability distribution, is an unobservable that is discovered as the ball is actually being squeezed. The values are discovered through the effort required to actualize them. When pressure on the ball is released, the probable relation of its molecules is no longer outweighed by an external dissipation and so reasserts itself.

An implication is that the test of a hypothesis regarding an emergent or historical process is not whether it generates testable predictions based on inferences from phenomena, but whether theory based on the discovery of non-actual probabilities makes constructive action possible.

\subsection{Action as a contradiction}

In folk science, action typically refers to a change in an actuality's observable state. However the argument has been that this is one-sided, and action cannot be understood as if the actuality were in isolation, such as a classic thermodynamic system. Instead, explaining action requires starting with a basic principle of the physical domain: ontological monism's immunity to miracles. What is fundamental in the physical domain cannot be created or destroyed. This is known as the "principle of conservation" (Earman 2004), and on it existence depends (Engels 1940, 37).

Conservation in the physical domain is usually discussed in terms of energy-mass. That is, while energy-mass can be transferred and transformed, it cannot be created or destroyed. One reason to see ontic probabilities as fundamental rather than energy-mass is that the latter probably implies closed units and thus a mechanistic explanation blind to emergence. Also, there is a host of processes in the physical, biological and human domains that must respect the laws of physics but do not reduce to physical properties. Conservation here refers to the value of actual ontic probabilities, for they alone ground.

Assuming this substitution in the conservation principle of ontic probability for energy-mass to be legitimate, actualities in the physical domain that participate in a conservation of net probability value represent a "symmetry group." The net sum of a group's actual probability values must conserve the value it inherited from its parent group (Martin, 2003b, 30-36). The symmetry group is not mereological, for it is not a container of actualities but merely the sum of their values. 
Taking some liberties with convention, the symmetry of a group refers to a situation in which actual values are maximally probable in reference to grounding actualities. An explicit symmetry break results from the introduction of a new exogenous ground that changes what is maximally probable. However, this cannot violate the principle of conservation. As a new probability value becomes actual, there must be an equal and opposite change of a value in the group so that its net value is conserved. If the new ground brings a propensity to dissipate, it must be balanced by an emergence. The new ground does not cause novelty, but merely enables it by breaking the group's symmetry. Action is here not the effect of an empowered agent, but the interdependence of emergent and dissipative propensities; you can't have one without the other in equal degree.

This begs for an example. A conventional one is a hypothetical pencil perfectly balanced on its point. It lacks orientation because the pencil's actual ground makes all possible orientations equally accessible. Now introduce a little puff of air that makes the probability of orientations asymmetrical. One orientation becomes more probable than the others, but this is not the cause of the pencil's actualization of orientation. It is rather the interdependence of the propensities for the emergence of orientation and the dissipation of gravity. The latter is not an independent engine of change but occurs because of the interdependence of two opposite action potentials.

While a causal explanation appears simpler, it is in fact profoundly more complicated. If the puff of air is seen in causal terms, it is an external force that begs for explanation, and this leads to infinite regress. The result is that in the absence of objective ideal forces, satisfactory causal explanations can only be short-range. Action is viewed instead as the unity of equal and opposite propensities. It is not change, but stability that calls for explanation.

Because symmetry is a mathematical concept specific to the physical domain, a more general term will be used instead, that of "contradiction" (Marquit 1988). Unfortunately this word is ambivalent (Marquit 2011). It has been defined as a logical contradiction resulting from cognitive closure, as a Hegelian subject-object dialectic or in folk science as incompatible empirical trajectories. Here it will simply refer to equal and opposite changes in the probability values of the actualities in a symmetry group that conserve its net probability value. To avoid confusion, when it comes to a logical contradiction it will be specified as such.

Mutual grounding gives actualities a propensity to move toward their net conserved value and form a persistent structure. However, net value is also conserved if the values of the actualities move equally away from the conserved value. The mechanisms for these two kinds of regular action, for contradictions to become respectively "shallow" or to "deepen," will be discussed next. The case of radical action will be put off until biological domain.

\subsection{The immediate and mediated locking of actualities}

In folk science, action is a change in the properties of observables over time, but it is seen here instead as a contradiction, as an interdependence of equal and opposite change in actual probability values that conserves existing value. This is the case whether those probability values approach each other or diverge. This interdependence will be referred to as a "lock." A lock in which actualities move toward their net value will be named an "immediate lock," while action in which they move away from it a "mediated lock."

An example of immediate locking is a voltmeter. When not connected to a circuit its needle points to zero because that position is mechanically most probable. However, when connected to a circuit's improbable voltage, the needle moves to the new position that has become maximally 
probable because of the new ground of circuit voltage. The more improbable the voltage, the more improbable is the needle's position in relation to its self-ground. The voltage and needle are locked even though they have no empirical relation. Of course the joint improbability of the needle's position and circuit voltage it must balance a dissipation in their environment. This is a drain on the voltage of the circuit being measured. Because this affects the reading, digital voltmeters with a reduced self-ground have generally replaced analog meters.

Whether action is a convergence or a divergence of probability values, a net emergence of value balances a net dissipation of value. Short of a convergence becoming maximally probable and form a structure, the lock of these opposite propensities is a contradiction. While convergent values spontaneously move toward the probable relation of their self-grounds, divergent values depend on a mediating structure. This mediation is given a variety of names such as diode, catalyst, barrier, surfactant, tool and wall, but here the generic and familiar term "interface" will be used.

The interface supports a divergence of probability values, a "deepening" contradiction, because of its asymmetric structure or dual sets of properties. One face or set of properties is immediately locked with the emergent actuality and the other face or set of properties is immediately locked with the dissipating actuality. It establishes a zero-sum relation of their change in probability on the condition that its self-ground is weightier than the probabilities it grounds.

An example of an interface with different sets of properties that support a contradiction is a tool such as a screw driver. Like the pivot of a teeter board, the tool itself does no work, and its self-ground conserves its structure despite wear and tear. One end of the screw driver immediately locks with the hand, while the other immediately locks with the screw. The dissipative effort turning the screwdriver balances the screw's improbable insertion. Anthropocentrism encourages thinking that it is a person's intent and effort that cause insertion, but in naturalistic terms the two are simply locked by an interface - are interdependent in terms of probability value and mutually enabling. That is, seeing things in terms of contradictions makes objectivity possible-or more accurately, dissolves the hypostatization of subject and object, of cause and effect.

An example of mediated locking by asymmetric interfaces is historiography. It cannot in principle engage a past that no longer exists and so refers to the relation of an emerging conception of the past and its existing representation. What distinguishes it from fiction is the presence of the asymmetric interfaces of evidence and socially constructed theory. Evidence refers to traces that happen to persist worked up to suit historiographic production. Theory locks the discoveries of past investigation on one hand and present individual thought on the other (see for an analogy, Feyerabend 1966). In both cases the result is ideological (one-sided) because grounded by the personality, interests and values of the historian who is a class member in contradictory society.

The utility of a historical conception is not whether it supports epistemic prediction or is truthful in relation to an imagined past, but rather the extent to which it supports a representation of the past that is grounded by the evidence, references a prevailing paradigm, is responsive to the personal character of the investigator and at the same time is creative. Historical consciousness thus enables creative action that is practical in the actual world.

Short-range history is well grounded by traces of the past, but its causal analysis is unresponsive to a discovery of non-actual probabilities. Although it may be provocative to say, short-range history therefore fails to support historical consciousness. It offers a particular person an identity because of the person's own connection with an immediate past that acquires meaning because of its spatio-temporal proximity. Universal history on the other hand finds all pasts to be equally instructive, however remote in time and place. 


\section{The Radical Emergence of the Biological Domain}

Although living organisms are physical, the biological domain introduces a radically new kind of behavior, that of "life." Albeit circular, argued will be that a living organism transcends the physical domain because it constructs a historical ground that references existents but is a probability vector does not reduce to them.

Defining life has not been easy (Cleland and Chyba 2002). Definitions are often a list of functions associated with life such as metabolism, evolution and the reproduction of information. Evolution does not seem relevant because organisms that are clearly alive may not evolve for many millions of years. Also, evolution refers to populations, not to individual living organisms. Reproduction and metabolism also fail to be definitive, for while they are certainly conditions necessary for life they exist in the physical domain and can be replicated in the laboratory with non-living hydrocarbon molecules (Luisi 2007).

\subsection{Informed choices}

An obvious distinction of life, as opposed to just a description of its functions or necessary conditions, is that while in the physical domain dissipation - the path of least action-is probable, in the biological domain the opposite is the case (Brillouin 1949). Being alive means perpetuating improbable action potentials by making choices that do not reduce to the determinations of circumstance (Brembs 2011). So improbable choices seem a useful place to start.

A choice is a discrimination that transcends its objects and depends on an independent criterion by which to reduce its objects to what is relevant to the criterion. Choices cannot be enabled by the ground of an evolved genotype because what persists from the past does not convey such a criterion (Singer 1996). What grounds life must be a structure that is constructed by action in the present. In folk psychology this ground is intentionality. Not only does this impose a mind-body dualism, but as will be illustrated shortly simple organisms lacking a central nervous system do in fact make choices (Bitbol and Luisi 2004). Furthermore, neurology suggests that conscious intentions may be more an effect of action than its cause (Libet 2002).

Choices sustain an organism's improbable action potential. In the biological domain improbable action potentials are constructed by metabolism-a recursive set of chemical reactions that yield complex organic molecules that support a reproduction of the improbable state of being alive. However, metabolism in hypothetical isolation and thus grounded solely by existent molecules would support only a regular emergence, the path of least action rather than choice. An emergence that is radical in reference to the physical domain must be informed by a structure that does not reduce to existing circumstances (Hochachka and McClelland 2014). In biochemistry, the lack of such a ground would lead to a random chemistry or a combinatorial explosion inimical to life (Pohorille 2009, 567). First to consider here is the historical ground that provides access to radical action.

The motive of biological action is a "need"- the extent to which an organism's action potential is insufficient to maintain its life. Improbable choices to meet needs must be balanced by the dissipation of environmental improbabilities such as nutrients. These action potentials are discovered by an organism taking action in its environment, and from that information is constructed a grounding structure. But this in itself is insufficient; when you squeeze the rubber ball you have little reason either to increase or reduce the pressure. Needed is historical information about how 
environmental action potentials have changed as the result of action. If they have declined, it represents a greater need that calls for an intensification of effort or a movement to where there is a higher nutrient density.

This probability differential is a "historical ground," not in the sense of an empirical difference between states at two points in time, but a vector that indicates the direction and magnitude of change in specific environmental probabilities that do not reduce to existents (Declerck 2012). It is a discovery of a change in probability values rather than reduce the world one-sidedly to just observable phenomena. If that value has declined, reproduction interprets it as a call for corrective action such as modifying an organism's interface with its environment.

An individual cell has an improbable state that depends on its separation from its environment by a membrane interface, which is an asymmetric amphiphilic bilayer of complex molecules. Unlike the physical domain, this interface is malleable in terms of its qualities and so is responsive to choice. A cell regulates its relation with its environment either by altering the properties of its membrane or by using it to move in the environment (Pohorille 2009). However, this still leaves out how the mechanism of choice arose in the first place. This will be explained by viewing the cell not as an isolate, but as a social being right from the start.

It should be noted that the rubber ball analogy fails at this point, for the most probable relation of its molecules is the immediate lock of their self-grounds. This persistent lock was simply outweighed by outside pressure. While some are inclined to posit this hysteresis as the key to life, the rubber ball on its own cannot make choices and must always pursue the path of least action. Thus a mere description of the emergence of living organisms from organic compounds such as animo acids fails to explain how life radically broke from the physical domain and lacks what Henri Bergson called an élan vital.

\subsection{Social Being}

How life arose in the first place will be adventurously attributed to "social being." This concept is not given an anthropological or sociological meaning nor even the conventional biological meaning of the phenotypical effect of social interactions. Instead it refers here to a process that is grounded by the difference of actual and non-actual probabilities. This will here be understood very broadly as the discovery and actualization by the actual self of the radical improbabilities made accessible by the grounding of another radically improbable structure.

Viewing life as a process rather than entity avoids the logical problem of suggesting life initially arose from sociality and is thus social prior to the life of the individual living organism (Gilbert, Sapp, and Tauber 2012). This problem arises because we generally view the earliest life forms, single-celled archaea and bacteria (or the Lowest Common Ancestor), as isolates despite the fact that the earliest evidence for them is of their association (Noffke et al. 2006).

An association of metabolism and reproduction can arise from a selective incorporation of the artifacts of the living action of other organisms. For example, there can be a lateral transfer of free floating RNA or genes (Sapp 2009; Beiko et al. 2005), particularly those related to the metabolism's construction of action potentials (Rivera et al. 1998). These molecules are not alive, but rather are radically improbable artifacts of life. An appropriation of radically improbable value constructed by others to ground the radical emergence of self may not be unexpected, but by presuming life the question remains begged. 
More helpful in this respect is endosymbiosis (Nowack and Melkonian 2010). It is increasingly felt that life started as an association of independent non-living organelles that gradually lost their independence to give rise to life. Popular is Lynn Margulis' serial endosymbiont hypothesis that mitochondria, chloroplasts and other organelles originated as non-living isolates that a non-living vesicle absorbed and upon which it came to depend for its improbable state (Sneed 2015).

Manfred Eigen and Peter Schuster (Eigen and Schuster 1979) explain this by arguing that life started as a recursively organized hypercycle of reproductive and metabolic catalytic cycles in which each cycle creates reactants for the other. In functional terms, action enabled by a metabolic cycle discovers the degree that the reproductive cycle has been successful, and this informs choices. No one cycle is in itself alive, but their organized association informed by historical information does support life. Eigen and Schuster employed the model of Darwinian evolution to explain why the hypercycle variant ("quasi-species") most effective in maintaining an action potential tended to prevail over other quasi-species and persist.

The $E$. coli bacterium will provide an example of two ways in which social being enables action that is radically improbable in relation to the physical domain. They arise from different interfaces. One interface is the cell wall. The other interface is constructed as the effect of a bacterium entering a probable relation with other bacteria. Important is that the former is what enables the latter, for the association of bacteria presumes they already have an action potential.

\subsection{The case of $E$. coli}

The $E$. coli bacterium is a single-celled organism enclosed in a selectively permeable membrane vesicle. This interface lets ions and nutrients in, while toxins are expelled. However, as Maxwell's Daemon shows, the interface in itself is insufficient to support choices that transcend circumstance (Brillouin 1951). Needed is a ground that is independent of existents.

E. coli discovers the probability density of nutrients in its environment by an improbable movement within it that dissipates its own metabolic action potentials. This movement lasts for about a second, and the result is a discovery of how nutrient probability density has as the result changed. This information defines whether or not the reproduction of its improbable state stands in need. If the probability density remains the same or has increased, a sensory receptor in the bacterium's membrane constructs a CheY molecule to signal its ion motors to spin flagella in a counterclockwise direction. This bundles them so that $E$. coli continues in its current path. However if nutrient density instead decreases, a phosphate is added to the CheY molecule to make it a CheZ molecule to represent a likely increased need. It signals the flagella to rotate instead in a clockwise direction, which unbundles them so that the bacterium remains in place. Its orientation nevertheless changes because of Brownian motion, and after a pause it explores the new direction (Berg 2006). Note that the structure of the two molecules does not correspond with the empirical nature of the nutrients engaged by E. coli's sensory organelles, but are rather a function of their changing probability values discovered through action.

Social action by E. coli's organelles informed by historical information admittedly offers a rather limited choice. On its own E. coli cannot decide where go because it lives in a onedimensional world, leaving it only the option to stop or go. However, another kind of radical action becomes available because of its social action in the present. Bacteria tend to enter a probable relation and thus form a community structure - a biofilm or bacterial mat (Waters and Bassler 2005). This structure grounds movement in three dimensions-an action not accessible to indi- 
vidual bacteria. Because social existence is not reified to serve as a causal factor, but is a mutual discovery of possibilities through joint action, social existence enhances rather than constrain individual capabilities (Jacob et al. 2004).

This implies that a transcendental social being and a radically improbable individual action refer to the same process rather than to a mereological dichotomy of self and other. The action of organelles within a particular cell and the social being of bacteria in a mat are both a discovery of non-actual probabilities that are abstract in reference to existents. The social being of organelles, individual organisms and even individuals from different species makes behaviors accessible that are beyond the reach of the hypothetical isolate (Fredrickson 2015). This understanding depends on the grounding of non-actual probabilities and so is not accessible to the method of reductive abstraction. It can only be acquired through the method of constructive abstraction.

\subsection{Personality and the self}

It follows that the more improbable the outcome of social action the wider are the possibilities accessible for an organism's improbable emergence. Social being enhances the individuated action of crabs (Laidre 2010) and insects (Dussutour, Deneubourg, and Fourcassié 2005). Even plants can recognize themselves and their kindred and choose whether or not to cooperate with them (Chen, During, and Anten 2012; Biedrzyck et al. 2010). Because social being makes probabilities accessible beyond those of self-grounding, organisms acquire personality in the sense of individuation. This is not a random deviation, for the individuated action is functional.

The word personality conventionally refers to the effect of the mind's unique development on character and action. However, the ontic probability fundamentalism of this paper makes individuation, other than merely a random mutation or deviation amplification, what is enabled by discovery through action. It is why personality in the sense of individuated action exists even in single-celled organisms that lack a central nervous system (Boehm 2006). Personality should not be thought of as peculiarly human, but instead as a radical artifact of biological social being.

Of course the eventual centralization of a nervous system supported a far greater development of both kinds of radical action. For example, the distinction of a discovery of historical and social information through action arguably gave rise to the functions of a working and a long-term memory (Shomrat et al. 2008). Working memory includes an executive function that focuses attention by limiting sensory inputs to favor action that transcends them (D'Esposito et al. 1995). This rapid and complex computation independent of current sensory information is similar to the function of a computer's RAM. Long term memory, like a computer's hard disk, means an ability to rely on an agent's past experience. However, as Alan Turing pointed out, their union in a computer does not support choices that transcend circumstance. He felt that doing so requires a supernatural black-box able to transcend existents that he called an "oracle" (Soare 1996).

It is difficult to assess the presence of an episodic memory in animals in which the animal remembers itself as an agent in relation to past circumstances. However, it is becoming clear that many animals can recognize other individuals and themselves. Much of the work has been done with primates, but it seems, for example, that pigeons recognize themselves as individuals (Epstein, Lanza, and Skinner 1981) and arguably the gloomy octopus has an episodic memory (Pronk, Wilson, and Harcourt 2010). This ability to represent in mind one's own individuation is known as "primary consciousness." It is not yet the human self-consciousness that radically emerged from this primary consciousness. 


\section{The Biological Enabling of Species Being}

The third domain that is radically improbable in reference to its parent domain(s) is that of humanity, here named the domain of "species being." This term is a translation of Ludwig Feurerbach's Gattungswesen, which served to distinguish humans from other animals (Held 2009). Although the trend today is to minimize this distinction, it will here play a central role. Rather than being a quaint fossil, the term "species being" usefully points to the difference between being biologically alive and being human.

The difference is taken to be species being's ability to construct grounds for action that are radically improbable not just in reference to its parent domains, but radically improbable even in reference to its own domain. That is, the action of species being is not only physical in the sense of being contradictory and biological in the sense of making choices that support the reproduction of improbable life, but is to a degree is also sui generis. Argued will be that the ground for this radically improbable action is the extent to which present action is improbable in reference to past action.

While admittedly abstruse, this point nevertheless addresses a classic philosophical issue, which is how to explain creativity or free will. The paper's argument has been that the possibilities for novel action become accessible because of an exogenous ground, and in the biological domain this ground was an artifact of the discovery of changes in environmental probability values. In the case of species being, the ground of action is radically improbable in reference to the radical action of biological life.

Several things can be said right at the start about this new ground. To be radically improbable in relation to life's maintenance through a contradictory relation with nature, the ground of species being must emerge from a contradiction that is independent of the production of life's action potentials. This contradiction can only be located in human society as a social contradiction. Of course the radical emergence of species being must balance a dissipation of the action potentials that arise from life's contradictory relation with nature. Since these social action potentials depend on production of improbable value, species being requires a dissipation of the natural environment that is in addition to that needed for biological reproduction.

Addressed in this section is how in a probabilistic world biological evolution gave rise to radically improbable structures because what can happen eventually does happen if conditions allow. In the next section is discussed how and why these structures began to ground behavior peculiar to species being not accidentally but regularly. When this behavior becomes probable rather than accidental, it marks the beginning of the Archaic Socio-Economic Formation-species being's initial stage of development.

\subsection{The development of hominin action potentials}

There is little doubt that increasing action potentials (a deepening contradictory relation with the natural environment) was a hominin evolutionary trend well before the appearance of any distinctive human behavior inaccessible to other animals. There have been various theories to account for it. For a long time a biological reductionism attributed it to the evolution of a remarkably endowed species, that of Homo sapiens. Today this is no longer persuasive because not only do other species such as $H$. erectus and $H$. neandertalensis exhibit human-like behaviors (for example, Wade 2016), but there may be hints of it even earlier with the Australopicene genus (Ambrose 2001). In any case, biological evolution is only an enabling condition, not an actualization of species being. 
Popular is the peculiarly Western belief that humans are distinguished by a flexible opportunism made possible by the evolution of tools through cultural accumulation. However, it was argued here that rational choice is definitive of life and is not peculiarly human. A variety of animals have a culture that conveys the use of perhaps even compound tools (Hunt and Gray 2004). New Calidonian crows apparently enjoy a ratcheting tool culture (Holzhaider, Hunt, and Gray 2010). An example of this belief is the invention of a "neolithic revolution" by which the economic accumulation facilitated by agriculture made humans masters of their destiny. However, simple organisms such as ants growing fungus as their food by feeding it grass clippings (Benckiser 2010) can be skillful cultivators. While tool development does deepen the contradictory metabolic relation of an organism and its environment, it is not peculiarly human.

Others prefer to focus on cognitive ability, but in recent years it is less clear that humans are fundamentally different in terms of it (in general see Shettleworth 2009). As impressive as are Homo's cognitive skills, they are merely a quantitative development of behaviors already manifest in animals. Examples of remarkable animal intelligence abound (such as described by Emery and Clayton 2004 in a descendant of dinosaurs, by Zimmer 2008 in a mollusk and by Alem et al. 2016 in an insect). These include an ability to abstract, to manipulate symbols (if encouraged), to recognize the self and to plan. Popular recently is the idea that theory of mind (awareness of another's mental state) is peculiarly human, but it seems that great apes are capable of it (Krupenye et al. 2016). Cognitive skill is not peculiar to humans, and it has even been argued that with the development of species being cranial capacity actually shrank a bit, for genetically based cleverness was no longer quite so necessary (Bednarik 2014).

\subsection{The primary contradiction}

Emergent hominin action potentials draw attention to the contradictory relation with the environment. But what comes to distinguish humans from other hominins is that their action potential becomes partially unhinged from that contradiction. This is thanks to a socially constructed interface that supports another contradiction. Given these two contradictions, the biological contradiction in the case of species being will henceforth be named the "primary contradiction" because it is the source of action potentials on which depends a secondary "social contradiction" that separates action potentials from the primary contradiction thanks to its interface.

Important is not merely the existence of these two contradictions, but their existential interdependence. This is not just because the dissipative side of the social contradiction is the emergent side of the primary contradiction, leaving nature to take the brunt. The point is that to a degree, each contradiction is constructed by the other.

More specifically the primary contradiction is not simply a continuation of biological metabolism. The difference is usually indicated by calling the primary contradiction "economic production." However, the term will be avoided here because it implies a one-sided reification that disregards its essential dependence on the social contradiction. Argued is that the agent in the primary contradiction is the species being constructed by the social contradiction rather than simply a biological social being. However generic, the term primary contradiction will be used in lieu of economic production or metabolism to emphasize its dependence on the secondary contradiction.

The outcome of the primary contradiction is an improbable product, the dissipation of which supports human emergence. Thus of concern here is not its empirical specificity, but the improbability of its value. The word "value" has contradictory meanings in economics. In bourgeois 
economics value is the costs of production of a commodity with which it can be exchanged in the marketplace; in working-class economics it includes an emergent value created by labor in addition to the costs of production. In the biological domain, the improbable value arising from metabolism is an action potential that supports the improbable reproduction of life. Therefore what emerges from the primary contradiction if taken in hypothetical isolation are "use values;" they are useful in reference to life's reproduction and meeting existing needs. The next section will address needs resulting from the social contradiction in the domain of species being. They are radically improbable in reference to the primary contradiction and will be distinguished as "wants." Despite the word's connotation, wants will not be understood to be whimsical desires but as necessarily met to support our humanity, our species being.

The interface of the primary contradiction is conventionally referred to as the "means of production" (Bottomore 1991, 204-206). They include emergent physical structures such as tools, raw materials and productive facilities, and emergent social capabilities that are ideational (science and technology) and biological (the condition and availability of people for work). What distinguishes it from a metabolic interface is that it supports not only the emergence of use values, but also a surplus value actualized for the satisfaction of wants-today generally privately appropriated as profit. The aspect of the means of production that supports the satisfaction of wants is a "labor power" peculiar to species being.

The concept of labor power is not well defined in the literature. Here it is seen as the effect of the degree to which the producer of value has acquired species being and is thus able to create value radically independent of use value. A hypothetical fully automatic machine can produce use values to satisfy all existing needs, but without the input of species being it cannot satisfy wants.

In the biological domain there are times when the production of use value is inadequate to meet needs and times when it is more than what is needed. Ceteris paribus excess value lacks use; your Zen cat leaves its prey at the door. In the case of species being, however, some value is "appropriated." Value can be appropriated as use value to reproduce the conditions of production, but also an additional value actualized to meet socially constructed wants. It is a "surplus value" (Bottomore 1991, 529-531), not because it is more than what is needed for reproduction, but because its actualization basically addresses wants having little to do with the production of use values. It seems the size of surplus value relative to use value has increased in the course of human history.

Given these distinctions, which admittedly are not entirely conventional, one would expect evidence for the emergence of species being to be the actualization of surplus value to meet wants. Although this evidence is intermittent and contentious (Hovers and Belfer-Cohen 2006), it is clear that hominins such as perhaps $H$. erectus and definitely $H$. sapiens and $H$. neandertalensis were beginning to address wants.

\subsection{The peculiarity of species being}

The object is to identify action that is independent of biological social reproduction. Humans construct a social contradiction that gives rise to a ground radically independent of the primary interface and supports action that goes beyond addressing use values. It was manifest in Africa by $140 \mathrm{ka}$ and perhaps even before then. This behavior is often quaintly referred to as "modern" but the term is avoided here because it implies a reified empirical coherence (as in Nowell 2010) constructed by a reductive abstraction. On the contrary, all Archaic trajectories appear to be complex and empirically unique (for examples see Ames 2004 and Fuller 2006). 
It is useful to provide some examples of behaviors that have little to do with biological reproduction. One such behavior is ritual. While rituals exist in the biological domain, in that of species being they can be independent of the primary contradiction. For example, ecstatic rituals are inferred from art works in which the self-reproducing social being is transcended to acquire a state of mind radically independent of the self. Music had perhaps a similar function.

It is clear that ritual feasting was a common practice (Arnold 1996) and could promote social solidarities unrelated to reproduction (Grimstead and Bayham 2010). Gift exchange or potlatch also cemented social relations and included those transcending local production (Tollefson 1995). Exchange networks exist in the biological world (for example, Simard et al. 2015), but in the domain of species being they could be unhinged from the production of use value. Another example was regional cult centers that supported a cooperation on basis far wider than just units of biological reproduction.

Another example of where human ritual is distinct from biological ritual is burials (Munro and Grosman 2010) and the provision of grave goods. They attribute to the individual a value that does not reduce to biology, for a dead organism cannot reproduce or provide use value. One can speculate that ritual burials took place because, to take liberties with John Donne, the death of another species being reduces the ground of one's own humanity.

Monuments ground consciousness with what no longer exists in the present. Other than an occasional time-keeping astronomical function they seem unrelated to production of use values. They appear among Pleistocene hunter-gatherers (Curry 2008) and by the Holocene are common. Of course there are monumental constructs in the animal world such as termite mounds, but they ultimately serve reproduction and are monumental in size, not monuments that bring something to mind that transcends sensory information about existents.

Language is frequently viewed as a force that liberates the person from circumstance because recursion makes it open ended. However, a recursive process, like chaos, is simply a determinate dynamical system having initial conditions too complex or subtle to support prediction; it is only epistemically open ended. Rather, language seems merely a biological precondition for species being. Also it is not certain that human language is distinguished by recursion (Gentner et al. 2006; Everett 2009). The kind of openness that enables species being is not epistemic unpredictability, but radical grounds that are artifacts of species being and independent of the production of use values.

\subsection{A liberating historical consciousness}

So the object is to explain how behavior that is radically improbable in relation to social reproduction and the production of use values could become grounded and thus accessible in the biological domain prior to its probable actualization as the domain of species being. While the argument parallels life's use of historical information to inform choices that transcend existents, it is suggested that species being employs a different kind of historical information.

A biological organism maintains an action potential that is radically improbable in reference to the physical domain by means of action that discovers a historical change in circumstantial probabilities. It is suggested that in contrast the historical ground of action peculiar to species being is based not on changes in circumstantial probability values but on changes in the improbability of action itself. The question is how such radical action was initiated. 
While animals are undoubtedly aware of the effort of their actions, that information only supports taking the path of least work needed to sustain life. Humans on the other hand transcend the production of just use values and a reproduction of phenotypical "human nature." These are merely conditions of species being. Unlike biological organisms, humans embrace the added effort to do what is radically improbable in order to meet wants and thus develop their humanity as transcendental agents.

This was traditionally explained in the West as an appropriation of divine creativity by a human nature made in god's image, a supernatural demi-urgos or a Prometheus. This mysticism survives today as an assumption that action is driven by an idea, value or goal rather than cognition being grounded in action. Some argue that creative behavior is simply the result of biological evolution: for example the development of a dopamine reward for creative action (Chermahini and Hommel 2010) and an oxytocin reward for pro-social behavior (Zak, Stanton, and Ahmadi 2007). However, this begs the question of why the rewards evolved in the first place. It might also seem reasonable to argue that technical innovation was self-perpetuating because it either reduced effort or increased the utility of the product. However, there is a profound difference between the regular emergence of technology in the biological domain and the radical emergence of species being.

The production of use values is regularly improbable in reference to action in the past and generates new needs because action potentials must balance a dissipation of environmental action potentials that are finite. While a variety of tactics can slow the emergence of needs, it is an unavoidable effect of being alive. On the other hand, action that is radically improbable in reference to action in the past not only deepens the primary contradiction but of itself generates new wants. This is because the action of species being is radically transcendent and generates new wants for that reason. The generation and satisfaction of radically emergent wants is what makes us human and is the source of human dignity.

Because action in the biological domain is primarily in thrall to the production of use values, any actualization of probabilities that are radically improbable in reference to biological need would initially have been accidental. This seems to explain why evidence for behavior peculiar to species being was at first so intermittent (Hovers and Belfer-Cohen 2006) rather than arise gradually from a cultural or genetic evolution. Radically improbable behavior accessible in the biological domain would have been of no consequence until it became probable, until its benefit was so widely recognized that an interface was constructed to institutionalize it.

\section{The Initial Stage of Species Being}

The consensus is that virtually everyone in the Archaic Socio-Economic Formation (as prehistory is here named) was either a producer of value (action potentials) or primarily lent support to its production. That is, virtually everyone is immediately locked by the primary contradiction's interface. This interface is asymmetric and is also immediately locked with the environment. In hypothetical isolation this arrangement would simply be biological metabolism, the construction of action potentials to reproduce improbable life. The mediated lock of producers and environment means that to live well you best use conventional means to do it.

But the method of constructive abstraction does not represent Archaic economic production as isolated. It was wedded to a social contradiction that constructed a ground for action radically independent of biological reproduction and the production of use values. Production by species being 
depended on the social contradiction for labor power just as the social contradiction depended on the primary contradiction for surplus value. While the emergence of the radical ground of species being has ultimately to balance environmental dissipation, as an artifact of a social contradiction it is empirically independent of production.

\subsection{The appropriation of surplus value}

It is agreed today that in the Archaic Socio-Economic Formation a ruling class was either lacking or at best only incipient. So it will now be adventurously argued that a radically improbable ground arose from a social contradiction located instead in the mind, between a producer's social being and the producer's species being. The question is how in the absence of an actual ruling class surplus value could be appropriated to address wants at the expense of producers' need to live. Some examples of this difficulty are worth mentioning.

It is frequently argued that, analogous to biological selection operating on the epistemically random mutation of genes, a deviation amplification in individual power, status and wealth in an originally "pristine" society evolved into social classes and eventually ancient states. However, it is doubtful this Darwinian model can be applied to social phenomena (Sperber and Claidière 2006). Also, ethology shows that inequality is common in the animal world, particularly among primates. Pristine equality turns out to be little more than Enlightenment ideology, for inequalities can characterize human hunter-gatherers (Killion 2013) and appear even among kindred (Testart 1989). Rather than being pristine and indicative of "human nature," social equality appears to have been constructed for reason (Runciman 2005).

Furthermore, an assumption that individual advantage is the engine of history and the reason for social relations being competitive also seems an artifact of Enlightenment ideology. The selfcontained individual is a construct peculiar to the modern West (Morris 1994). The resulting methodological individualism means that social relations offer nothing to the sacrosanct self but an opportunity to promote its own private advantage at the expense of others. In contrast, it is here argued that the dignity of being human is not won through the exploitation of others but becomes accessible through a joint struggle with others, a mutual discovery of species being (as in marriage and the labor union) or through access to public surplus value (as in public education). While the work to actualize this accessible species being depends ultimately on our contradictory relation with nature, it is immediately the work enabled by the social contradiction, or put more simply that of class struggle.

Some argue that the evolution of culture can ground radically improbable action (see Fracchia and Lewontin 1999 for a critique). To get around the problem that a regular emergence fails to offer a radical ground, it has been suggested that culture ratchets (Tennie, Call, and Tomasello 2009) and thereby breaks with its past. The difficulty is that ratcheting presumes a reification of socio-cultural totalities, when in fact every individual continually and selectively adopts and modifies the portions of culture to which that person happens to be exposed.

Artifacts of species being ground the emergence of species being because of their radical improbability in reference to existent actualities rather than because of their qualities. This artifactual grounding has reached an apogee today as technology brings people together at the global level despite their empirical differences (Aneesh 2015). In the Archaic stage it seems that exchanges between individuals at temporary aggregation sites became more extensive prior to the Holocene. Put broadly, species being was facilitated by larger social units with a more intensive social interaction, as seems to have been the case in joint child rearing. 
However, mutual grounding presumes that people are radically innovative to begin with, and so the underlying mechanism for it must be found. Anthropologists often look to a self-interested social agent to appropriate and actualize surplus value. While there were advantaged individuals in the Archaic Formation, they lacked a mechanism or motivation for such an appropriation (people could always vote with their feet to avoid it). So a mechanism of appropriation that does not depend on actual social classes is now be proposed.

\subsection{A cognitive social contradiction}

In the biological domain a failure to predict brings surprise and disappointment but not a belief that the world is inherently unpredictable. However with the development of hominin action potentials and as circumstances were increasingly of human construction, a failure to predict must have seemed unnatural. It is suggested that the result in folk psychology is a reification of supernatural forces or thaumaturges that stand outside a world that biological existence required to be predictable in principle.

It is further suggested that such a supernatural agent is a real cognitive entity that grounds a cognitive probability distribution to make radically improbable actions accessible in thought. This does not lend respectability to Descartes, for it is not suggested that the idea does work. The counterfactual cognitive entity merely grounds a cognitive probability distribution to make radically improbable actions accessible. Their actualization, however, is the result of work-a dissipation of nature's action potentials through the primary contradiction. So a social contradiction in the form of a consciousness that grounds value arising from the primary contradiction on one hand and supernatural cognitive entities on the other can inform action that is radically improbable in reference to biological reproduction.

These radically improbable cognitive entities constitute the "ruling class" in the Archaic Formation because in practice there seems to have been an array of supernatural forces or urgoi. They ruled in the sense that the appropriation of a surplus to satisfy wants was at the expense of the biological drive for social reproduction. While this argument may accord with how we know people act, it remains speculative and is certainly at odds with convention. However, the purpose has been to demonstrate that the method of constructive abstraction can provide a naturalistic explanation of species being that is beyond the reach of a reductive abstraction.

For there to be an Archaic Formation, action radically independent of existents had to become probable rather than just accidental. The supernatural had to become an institutionalized cultural belief that provided a regular interface between economic value and a supernatural world of the imagination. The supernatural could not exist without the dissipation of surplus value; surplus value could not exist without its supernatural appropriation. The two contradictions mutually deepen because they are both locked with the producing class.

Sociology refers to the interface of the social contradiction as "superstructure" (Bottomore 1991, 45-48), which today refers specifically to ideology and state. But the Archaic Formation lacked a state institution and, without written documents, ideology (cognitive entities that are functional in reference to the social contradiction) is difficult to infer.

An example of what can be inferred is a culture of sacrifices and ritual that left behind physical traces. These institutions encouraged a voluntary self-appropriation in the sense that the producer is willing to limit the satisfaction of needs so that there is a surplus value to meet wants. Shamanism, for example, mediated the lock between the supernatural and the producers of use value. 
Not dependent on the institutions that mediate the social contradiction is a mutual grounding of species beings through joint struggle, as in production. Through it is discovered the other person's species being, the representation of which can ground species being's becoming accessible to the self. Arguably this is the basis for the "dignity" of labor. In a successful marriage, as the partners struggle together to establish a transcendent unity, they become ever more fully human. The person's dignity is the radically improbable outcome of their labor that enables one's own emergence as species being. Because this emergence addresses human wants, it is a motivation.

The argument has assumed that the Archaic producer was to some extent a species being. This runs counter to the late $19^{\text {th }}$ century view that the producer is just another inert force of production unable to be creative (as illustrated by Millet's Man with a Hoe [1898]). While the Archaic producer's development as species being naturally lagged that of the ideal appropriating agent, the point is that, however modest, its possession by the producer was a real condition of surplus value. If productivity eventually reaches the point that the production of use values is fully mechanized and automated, the producer can ground production solely for the satisfaction of his or her wants as species being. At this point the need for superstructure to support the radical emergence of species being ends and is replaced by real democracy in which the development of society and the individual are one.

\subsection{The Archaic Socio-Economic Formation}

The initial stage in the emergence of species being has here been called the Archaic Socio-Economic Formation, although it is more conventionally known as either the primitive-communal stage (for example, in Momjan 1980, 45-50) or as "prehistory." The term prehistory is avoided because it implies a passive adaptation of a fixed human nature to changing circumstances; it fails to represent humans as constructing themselves as species beings by actualizing probabilities made accessible by a socially constructed ground independent of the production of use value. The term primitivecommunal is not used because it seems the Archaic Socio-Economic Formation was neither egalitarian nor lacking in individuation.

To suggest that human history has been a progressive actualization of species being accords, except for the terminology, with convention. Some even argue that this development has given rise to an entirely new geologic era, the anthropocene, although this point seems rather empty outside the discipline of geology. Because until now the satisfaction of wants has been at the expense of needs, the paper argued that the mechanism for the emergence of species being was necessarily a social contradiction. As the result, what marks stages in history are the persistent superstructures that enable social contradictions. For example, the social contradiction of the Archaic SocioEconomic Formation was arguably in the mind and transmitted by culture, while in subsequent social formations it involved the contradictory relation of actual social classes.

The meaning of "social class" here is not that of folk science, for it is not a reification of a set of persistent shared properties such as income level, nor are class relations viewed in terms of inequities. Such a definition can support the maintenance of social order, but it blocks explanation and thus social change. Classes are here defined instead in terms of their relation to the surplus value that supports the emergence of species being. The members of a class either create surplus value as the producing class or appropriate it as the ruling class. However, these simple functional terms only serve to elucidate the method of constructive abstraction. In fact at every stage in history the grounding of circumstance makes classes empirically complex, even ambivalent, and they acquire names reflecting those conditions. 
If human history is understood as our mounting ability to transcend circumstance to acquire species being, then of fundamental concern must be the grounds that make radical action accessible. This is why social classes represent "relations of production" (Edwards 1978): superstructure locks the producing class with the production of value and locks the ruling class with its appropriation (Abercrombie, Hill, and Turner 1988, 35-38). The aim of the argument has been the modest one of merely identifying the mechanism of social change, not the more challenging one of historiography, which brings together theory, rhetorical skill and empirical research.

It is not denied that social inequities can be source of contention, but addressing them only deepens contradictions. It does not introduce new relations of production and thus new possibilities for the development of species being. That is, protests or "bread and butter" struggles within a given set of productive relations might develop conditions favorable to revolution, but are not themselves revolutionary. Only class struggle in terms defined by the interface of the social contradiction can do that. This can take many forms. For example, a demand for dignity inherently challenges existing relations of production predicated on the appropriation of surplus value and thus a constraint on most people's species being.

\subsection{Revolutions as the joints of universal history}

In the West, historical subdivisions are reified cognitive constructs. Examples are a technological reductionism (as in the Paleolithic, Bronze and Information Ages), a reification of cultural totalities (as in civilization and Classical Antiquity) or an interaction of objectively ideal causal factors (as in modes of production or world systems). This idealism withers under the glare of empirical investigation (for example, Sassaman 2004). Many in the $20^{\text {th }}$ century have as the result despaired finding any scientifically warranted explanation of historical development and so retreat to the simple narrative and short-range causal explanation of folk science. Any history beyond that of individual private experience thereby loses shape or meaning and with it any hope that human self-transcendence is subject to an explanation that can inform a struggle for liberation.

It used to be conventional in universal history to find the course of human history analogous to biological evolution, with its speciation (types of society), vigorous youth, sclerotic advanced age and final death (fall) — often followed by a gratuitous new type of society. Today a historiography in the manner of Oswald Spengler or Arnold Toynbee has been largely abandoned as unscientific. Yet it does roughly describe commonly observed trajectories. There do seem to be distinctive social orders; their development does not seem random; they eventually collapse and are usually succeeded by a society that is less probable, such as being larger, more economically productive, more complex or more sophisticated. Just because explanations for this pattern have proven inadequate does not mean it does not exist or its explanation should not be ventured.

If human history is understood to be the emergence of species being, then historical divisions are best distinguished by their characteristic relations of production-the mechanism of that emergence. In order to function, interfaces must conserve their value despite empirical change, and so a revolutionary construction of new relations of production is eventually needed to ensure a continued satisfaction of wants and development of species being.

This gives history a stadial character, with each stage initiated by a revolution that opens new possibilities. Revolutions are the joints that lend shape to universal history, for they distinguish the periods of slow evolution enabled by the relations of production constructed by the prior revolution. The "evolution" of a particular stage is the mutual deepening of its primary and the social contra- 
dictions, which simultaneously gives rise to the action potentials that eventually make revolution possible and to the unmet needs and wants that make it necessary. This interdependence of the primary and social contradictions is why historical stages are called "socio-economic formations" (Semyenov 1980; Munshi 1991). The result is a "progressive" sequence of stages defined as an incremental actualization of species being. Technological progress is merely a necessary condition for rather than a definition of progress. Progress is always a struggle to actualize probabilities to satisfy wants peculiar to time, place and circumstance.

What is missing so far is a time dimension. The primary and social interfaces tend to persist, not only because an interface's self-ground is necessary for it to support a contradiction, but also because they are grounded by the outcome of the actions they make probable. This supports homeostasis and locks action potentials with old needs and wants. This dead hand of the past slows the pace of change, but of greater significance is that the depth of the contradiction provides a historical stage with a temporal dimension in relation to which particular events or entities acquire an objective long-term significance: their impact on the depth of contradictions, their contribution to the conditions for revolution and thus a further emergence of species being.

Note that the objective and subjective aspects of revolution here come together, for there is nothing automatic about revolution. Motivation is always required to actualize accessible probabilities. While revolution is objectively enabled and motivated by deepening contradictions, its actualization is the result of informed choice and joint struggle. The outcome of class struggle is revolution - the construction of new relations of production. The form this struggle takes, such as whether it is at the state level or the degree it is rapid or violent, is a function of circumstance.

For example, historical circumstances brought together a relatively weak superstructure and relatively great action potentials in $7^{\text {th }}$-century Europe. Mayors of the palace had the power to appropriate surplus value privately rather can be held back by the grounding of Ancient superstructure. This offered an exemplar for class struggle to complete the feudal revolution by the $10^{\text {th }}$ century as large numbers of milites and castelains rising from the producing class formed a large self-sufficient feudal ruling class. They used violent means to appropriate political (largely ecclesiastical) land and subject it to their private surplus appropriation.

Revolution makes the sequence of stages progressive, although this is no longer a fashionable belief. Besides the disheartening wars of $20^{\text {th }}$-century capitalism, another reason for pessimism is that the usual measure of progress is subjective. There is no universal criterion for it that suits everyone and all aspects of life. Here instead the criterion is the relative improbability of action potentials (whether employed for good or for ill) and the improbability of species being. This criterion is universal, for it is a probability that does not reduce to empirical specifics. In folk terms, an improbable action in the future that transcends the present is enabled and necessitated by the deepening of contradictions inherited from the past.

The aim here has not been to write a history of the Archaic Formation but merely to elaborate the method sufficient to do it. In historical terms some Archaic producers acquired greater action potentials than others. This was of no consequence until this elite modifies institutions in a way to address political needs through the appropriation of a surplus value from producers. Because this process is simultaneously objective and subjective, it avoids the old anthropological question of whether a transition to the Ancient Socio-Economic Formation was a way to address emerging political needs or was imposed by ambitious potentates.

An example of a historical approach to the revolutionary transition to the Ancient Social Formation might be the subjection of the supernatural to the private control of an elite (Marcus and 
Flannery 2004) or king. Ethnography suggests this brings with it police powers (Shariff, Norenzayan, and Henrich 2010), a surplus appropriation by an actual social agent standing outside production (Peoples and Marlowe 2012) and the legitimation of that appropriation because it brought a public service that reduced uncertainty (for example, Flad 2008). However, the interesting historiographic question of the transition from the Archaic to the Ancient, then Feudal and finally Capitalist Socio-Economic Formations lies outside the scope of this paper, concerned as it is with the method suited to universal history.

\section{Conclusion}

This paper attempted to recover the function of universal history that placed what is particular in relation to what is universal. However, it aimed to provide it with a method more robust and with a historical consciousness more assuredly liberating. This required a reconstruction of universal history in scientific rather than idealist terms. Proposed was the employment of the method of constructive abstraction rather than rely on that of a reductive abstraction, which appeals to an objective idealism to lend meaning to particulars.

Argued was that a scientific and materialist understanding of processes requires an expansion of the definition of matter to include unobservable ontic probabilities. To recover history as a process, and as one in which the individual species being is central, the paper appealed to a current and open notion of scientificity rather than to a positivist science. The tangible, observable, identity of actualities simply refers those ontic probabilities that happen to be maximally probable under the circumstances.

The method is universal in the sense that it ventures to explain any kind of process, be it physical, biological or human. While the scope that results makes a general conclusion difficult, the conclusion does offer an opportunity to elaborate certain of the paper's implications.

The old tension between the scientific and humanistic approaches to historiography seems a percipitate of a one-sided conception that views history as a systemic interaction of reified conceptions or factors inferred from phenomena rather than from discovery through action. Lost thereby is history as a process rather than a collection of effects; lost is empirical data that do not happen to support an ideal coherence or have immediate causal efficacy.

Also lost is that it is individual species beings that make history, although not just as they please. History is not made by reified cognitive entities such forces, laws, cultures, social groups or even individuals in isolation. The union of a discovery of social possibilities through joint struggle and the discovery of natural possibilities through production enables species being to transcend the dead hand of the past if contradictions are sufficiently deep and there is an informed effort. By representing human nature as a probability distribution, action is at once a social construct and true to the self. There is no contradiction of self and other.

Unlike Western humanism, which reduces the world to its meaning for the potent individual, the scientificity of this paper keeps humanity in communication with its physical and biological being. This is viewed as desirable these days as we seek to recover a workable relation with our environment and avoid ecological disaster. On the other hand, the paper's posthumanism underwrites freedom of choice and moral responsibility because action is grounded by both the emergent self and by circumstances that make possibilities accessible.

Implicit in the paper is that an understanding of historically situated species being begins with 
the observation of symptoms that mark the depth of contradictions in a particular time and place. The greater is this depth, the greater are both the action potentials and the unmet needs or wants relative to the past. It lends observables significance in relation to the development of species being, both in its evolution at a particular stage and for enabling the long-range revolutionary potential for bringing the development of species being to a higher level. As the result, long- and short-range history are reconciled.

Empirical facts have been called the alpha and omega of historiography. However, reducing explanation to them is one sided. The shorter the range of an historical account, the more do generalizations correspond with empirical specifics and lend warrant to narrative causal explanation. However, it is unrealistic to attempt long range historiography in such terms, marked as it is by overwhelming empirical diversity and profound change in time. In the absence of information acquired through action, explanation beyond the parochial looses warrant. The aim was not to discredit short range narrative, but to suggest that all historical study is both closed and open, situated between the short- and the long-range. Universal history depends on short range analysis to engage the ground of actualities and short-range history depends on universal history to engage the possibilities for change. Each depends on the other.

One reaction to positivism has been postmodernism's dismissal of science altogether as a metanarrative. Yet because action in the world is the source of action potentials and science is a knowledge based on that action, the language of science is the only universal language. It offers the only basis for global communication and must be the language of a universal history. However, the paper began with an example of how the language of science is ideological. This is not inconsistent, for science is a cognitive artifact of action. While action is universal in that it engages matter in all its forms, the cognitive processing of that information is grounded by self and so in a contradictory society is inherently ideological. Rather than being false, it is one-sided under that circumstance.

A Buddhist would understand that because action is particular, humanity's relation with the world is contradictory. So it might seem the paper's argument implies that technological advances can only delay inevitable environmental catastrophe (as Sebastiano Timpanaro has argued). The necessarily ever greater improbability of human action is purchased by an ever greater dissipation of the environment on which that action depends. However, with the full actualization of species being, action becomes universal in that physical, biological and human existence become aspects of one process; environment and humankind then cease to stand in a contradictory relation. Without superstructure anything possible under the circumstances becomes accessible, such as the development of an effectively unlimited power source and a dispersion of heat away from the earth.

It was once thought that historical consciousness was liberating because it conveyed ideal possibilities. For example, prodigiously expensive historiographic infrastructures were constructed in the $19^{\text {th }}$ century Europe such as the Monumenta Germaniae Historica in the belief that human development depended on the state's actualization of ideal possibilities that can ground individual Bildung or liberty. As the state became increasingly problematic in the $20^{\text {th }}$ century (Auschwitz and Hiroshima come to mind), an alternative explanation of development came from Darwinian models of social evolution, which seemed to lend support to a dialectic of preservation of the past and a competitive struggle for progress in the present. This model faltered under a siege of criticism, and nothing has replaced it.

While there are a few historians who still believe that political history has a civilizing effect or that radically transcendent powers can emerge from biological evolution, historiography has generally lost its social utility. It provides ideological support for the present order as a necessary 
outcome of objective factors that leaves the individual little efficacy. This is perhaps an overly dismal assessment, but little remains today of any serious justification for historical consciousness as needed for human liberty. The paper attempted to recover it through a scientific understanding of how historic processes actually work.

The method of constructive abstraction engages the conditions necessary for human dignity and the mechanism by which it is constructed. This is not a cosmopolitanism in which people's empirical differences somehow become appealing if kept at a safe distance, nor is it a humanism in which the world reduces to the ego of the powerful. Rather, the argument was that the actualization of human dignity depends on the mutual grounding of maximally individuated species beings, their gaining access to surplus value and the struggle to actualize them . 


\section{References}

Abercrombie, Nicholas, Stephen Hill, and Bryan S. Turner. 1988. The Penguin Dictionary of Sociology. 2nd ed. London (GBR): Penguin. (Pg. 25).

Alem, Sylvain, Clint J. Perry, Xingfu Zhu, Olli J. Loukola, Thomas Ingraham, Eirik Søvik, and Lars Chittka. 2016. "Associative Mechanisms Allow for Social Learning and Cultural Transmission of String Pulling in an Insect." PLOS Biology 14, no. 10 (April): e1002564. doi:10. 1371/journal.pbio.1002564. (Pg. 18).

Ambrose, Stanley H. 2001. "Paleolithic Technology and Human Evolution." Science 291 (5509): 1748-1753. doi:10.1126/science.1059487. (Pg. 17).

Ames, Kenneth M. 2004. "Supposing Hunter-Gatherer Variability." American Antiquity 69 (2): 364-374. doi:10.2307/4128427. (Pg. 19).

Anderson, Philip W. 1972. "More Is Different: Broken Symmetry and the Nature of the Hierarchical Structure of Science." Science N.S. 177, no. 4047 (4 August): 393-396. doi:10.1126/ science.177.4047.393. (Pg. 7).

Aneesh, A. 2015. "Emerging Scripts of Global Speech.” Sociological Theory 33 (3): 234-255. doi:10.1177/0735275115600736. (Pg. 22).

Arnold, Jeanne E. 1996. "The Archaeology of Complex Hunter-Gatherers." Journal of Archaeological Method and Theory 3, no. 1 (March): 77-126. doi:10.1007/bf02228931. (Pg. 20).

Audi, Paul. 2012. "A Clarification and Defense of the Notion of Grounding." In Metaphysical Grounding: Understanding the Structure of Reality, edited by Fabrice Correia and Benjamin Schnieder, 101-121. Cambridge (GBR): Cambridge University Press. doi:10.1017/cbo978113 9149136.004. (Pg. 8).

Balasubramanian, Vijay. 2011. "What We Don't Know about Time." Foundations of Physics 43:101114. doi:10.1007/s10701-011-9591-y. (Pg. 8).

Bedau, Mark A., and Paul Humphreys, eds. 2008. Emergence: Contemporary Readings in Philosophy and Science. Cambridge, MA (USA), MIT Press, Bradford. (Pg. 9).

Bednarik, Robert G. 2014. "Doing with Less: Hominin Brain Atrophy." HOMO_Journal of Comparative Human Biology 65 (6): 433-449. doi:10.1016/j.jchb.2014.06.001. (Pg. 18).

Beiko, Robert G., Timothy J. Harlow, Mark A. Ragan, and Carl R. Woese. 2005. "Highways of Gene Sharing in Prokaryotes." Proceedings of the National Academy of Sciences of the United States of America 102, no. 40 (4 October): 14332-14337. doi:10.1073/pnas.0504068102. (Pg. 14).

Bell, John S. 2004. "Beables for Quantum Field Theory.” Chap. 19 in Speakable and Unspeakable in Quantum Mechanics, 2nd ed., 173-180. Cambridge (GBR): Cambridge University Press. doi:10.1017/cbo9780511815676.021. (Pg. 5).

Benckiser, Gero. 2010. "Ants and sustainable agriculture. A review." Agronomy for Sustainable Development 30 (2): 191-199. doi:10.1007/978-94-007-0394-0_2. (Pg. 18). 
Berg, Howard C. 2006. "Marvels of Bacterial Behavior." Proceedings of the American Philosophical Society 150, no. 3 (September): 428-442. http://www.jstor.org/stable/4599006. (Pg. 15).

Biedrzyck, Meredith L., Tafari A. Jilany, Susan A. Dudley, and Harsh P. Bais. 2010. "Root Exudates Mediate Kin Recognition in Plants." Communicative \& Integrative Biology 3, no. 1 (January-February): 28-35. doi:10.4161/cib.3.1.10118. (Pg. 16).

Bigelow, John, Brian Ellis, and Robert Pargetter. 1988. "Forces.” Philosophy of Science 55, no. 4 (December): 614-630. doi:10.1086/289464. (Pg. 4).

Bitbol, Michel, and Pier Luigi Luisi. 2004. “Autopoiesis with or without Cognition: Defining Life at its Edge." Journal of the Royal Society Interface 1 (1): 99-107. doi:10.1098/rsif.2004.0012. (Pg. 13).

Boehm, Thomas. 2006. “Quality Control in Self/Nonself Discrimination.” Cell 125, no. 5 (2 June): 845-858. doi:10.1016/j.cell.2006.05.017. (Pg. 16).

Bossuet, Jacques Bénigne. 2010. An Introduction to, or a Short Discourse Concerning, Universal History. In two parts. Faithfully compar'd with, and done ... from James Benigne Bossuet ... by Richard Spencer [1681]. Farmington Hills, MI (USA): Gale ECCO. (Pg. 1).

Bottomore, Tom, ed. 1991. A Dictionary of Marxist Thought. 2nd ed. Oxford (GBR): Blackwell. (Pp. 19, 23).

Boyd, Richard. 1991. "On the Current Status of Scientific Realism." Chap. 11 in The Philosophy of Science, edited by Richard Boyd, Philip Gasper, and J. D. Trent, 195-222. Cambridge, MA (USA): MIT Press. (Pg. 5).

Brembs, Björn. 2011. "Towards a Scientific Concept of Free Will as a Biological Trait: Spontaneous Actions and Decision-making in Invertebrates." Proceedings of the Royal Society B: Biological Sciences 278, no. 1707 (22 March): 930-939. doi:10.1098/rspb.2010.2325. (Pg. 13).

Brillouin, Léon. 1949. “Life, Thermodynamics, and Cybernetics.” American Scientist 37:554-568. (Pg. 13).

1951. "Maxwell's Demon Cannot Operate: Information and Entropy." Journal of Applied Physics 22, no. 3 (March): 334-343. doi:10.1063/1.1699951. (Pg. 15).

Brown, Haines. 2014. “A Process Ontology.” Axiomathes 24, no. 3 (September): 291-312. doi:10. 1007/s10516-013-9219-2. (Pg. 8).

Brzechczyn, Krzysztof. 2009. "Methodological Peculiarities of History in Light of Idealizational Theory of Science.” In Idealization XIII: Modeling in History, edited by K. Brzechczyn, 137157. Pozna Studies in the Philosophy of the Sciences and the Humanities, vol. 97. Amsterdam (NED): Rodopi. (Pg. 6).

Butterfield, Jeremy. 2006. "Against Pointillisme about Geometry." In Time and History, edited by Friedrich Stadler and Michael Stöltzner, 181-222. Proceedings of the 28. International Ludwig Wittgenstein Symposium, Kirchberg am Wechsel, Austria 2005. Berlin (GER): De Gruyter. doi:10.1515/9783110333213.181. (Pg. 3). 
Capek, Milec. 1981. "Time in Relativity Theory: Arguments for a Philosophy of Becoming." In The Voices of Time: A Cooperative Survey of Man's Views of Time as Expressed by the Sciences and by the Humanities, edited by J. T. Fraser, 434-454. Amherst, MA (USA): University of Massachusetts Press. (Pg. 9).

Cartwright, Nancy. 1983. How the Laws of Physics Lie. Oxford (GBR): Clarendon. (Pg. 4).

Chalmers, David J. 2006. "Phenomenal Concepts and the Explanatory Gap.” In Phenomenal Concepts and Phenomenal Knowledge: New Essays on Consciousness and Physicalism, edited by T. Alter and S. Walter, 167-194. New York, NY (USA): Oxford University Press. doi:10.1093/ acprof:oso/9780195171655.003.0009. (Pg. 4).

Chen, Bin J. W., Heinjo J. During, and Neils P. R. Anten. 2012. "Detect thy Neighbor: Identity Recognition at the Root Level in Plants.” Plant Science 195:157-167. doi:10.1016/j.plantsci. 2012.07.006. (Pg. 16).

Chermahini, Soghra Akbari, and Bernhard Hommel. 2010. "The (b)link between creativity and dopamine: Spontaneous eye blink rates predict and dissociate divergent and convergent thinking." Cognition 115 (3): 458-465. doi:10.1016/j.cognition.2010.03.007. (Pg. 21).

Churchland, Paul M. 1989. "Folk Psychology and the Explanation of Human Behavior." Philosophical Perspectives 3:225-241. doi:10.2307/2214269. (Pg. 3).

Clark, Michael J., and David Liggins. 2012. "Recent Work on Grounding." Analysis 72 (4): 812 823. doi:10.1093/analys/ans086. (Pg. 8).

Cleland, Carol E., and Christopher F. Chyba. 2002. "Defining 'Life'." Origins of Life and Evolution of the Biosphere 32 (4): 387-393. doi:10.1023/a:1020503324273. (Pg. 13).

Cross, Andrew. 1991. "The Crisis in Physics: Dialectical Materialism and Quantum Theory." Social Studies of Science 21, no. 4 (November): 735-759. doi:10.1177/030631291021004005. (Pg. 2).

Cross, Troy. 2012. "Recent Work on Dispositions.” Analysis 72, no. 1 (January): 115-124. doi:10. 1093/analys/anr144. (Pg. 5).

Curry, Andrew. 2008. “Seeking the Roots of Ritual.” Science 319, no. 5861 (18 January): 278-280. doi:10.1126/science.319.5861.278. (Pg. 20).

Declerck, Gunnar. 2012. "Incarnation, motricité et rapport au possible.” Studia Phaenomenologica 12:35-60. doi:10.7761/sp.12.35. (Pg. 14).

D’Esposito, Mark, John A. Detre, David C. Alsop, Robert K. Shin, Scott Atlas, and Murray Grossman. 1995. "The Neural Basis of the Central Executive System of Working Memory." Nature 378, no. 6554 (16 November): 279-281. doi:10.1038/378279a0. (Pg. 16).

Dieks, Dennis. 2006. "Becoming, Relativity and Locality." In The Ontology of Spacetime, edited by Dennis Dieks, 1:157-176. Philosophy and Foundations of Physics. Amsterdam (NED): Elsevier Science. doi:10.1016/s1871-1774(06)01008-4. (Pg. 3).

Dirlik, Arif. 2005. "Performing the World: and Representation in the Making of World Histor(ies)." Journal of World History 16 (4): 391-410. doi:10.1353/jwh.2006.0016. (Pg. 2). 
Dorato, Mauro. 2006. "Absolute Becoming, Relational Becoming and the Arrow of Time: Some Non-Conventional Remarks on the Relationship between Physics and Metaphysics." Studies in History and Philosophy of Modern Physics 37:559-576. doi:10.1016/j.shpsb.2006.03.003. (Pg. 9).

Duara, Prasenjit. 1998. "Why is History Antitheoretical?” Modern China 24, no. 2 (April): 105120. doi:10.1177/009770049802400202. (Pg. 1).

Dussutour, Audrey, Jean-Louis Deneubourg, and Vincent Fourcassié. 2005. "Amplification of Individual Preferences in a Social Context: The Case of Wall-Following in Ants." Proceedings: Biological Sciences 272, no. 1564 (7 April): 705-714. doi:10.1098/rspb.2004.2990. (Pg. 16).

Earman, John. 2004. "Laws, Symmetry, and Symmetry Breaking: Invariance, Conservation Principles, and Objectivity.” Philosophy of Science 71, no. 5 (December): 1227-1241. doi:10.1086/ 428016. (Pg. 10).

Edwards, Richard C. 1978. "The Social Relations of Production at the Point of Production." Critical Sociology 8 (2-3): 109-125. doi:10.1177/089692057800800213. (Pg. 25).

Eigen, Manfred, and Peter Schuster. 1979. The Hypercycle: A Principle of Self-Organization. Berlin (GER): Springer. (Pg. 15).

Emery, Nathan J., and Nicola S. Clayton. 2004. "The Mentality of Crows: Convergent Evolution of Intelligence in Corvids and Apes." Science N.S. 306, no. 5703 (10 December): 1903-1907. doi:10.1126/science.1098410. (Pg. 18).

Engels, Frederick. 1940. Dialectics of Nature. New York, NY (USA): International Publishers. (Pp. 8, 10).

Epstein, Robert, Robert P. Lanza, and Burrhus Frederic Skinner. 1981. “'Self-Awareness' in the Pigeon.” Science 212, no. 4495 (8 May): 695-696. doi:10.1126/science.212.4495.695. (Pg. 16).

Everett, Daniel L. 2009. "Pirahã Culture and Grammar: A Response to Some Criticisms." Language 85, no. 2 (June): 405-442. doi:10.1353/lan.0.0104. (Pg. 20).

Feyerabend, Paul K. 1966. "Dialectical Materialism and the Quantum Theory." Slavic Review 25, no. 3 (September): 414-417. doi:10.2307/2492853. (Pg. 12).

Field, Douglas P., and Philip N. Hineline. 2008. "Dispositioning and the Obscured Roles of Time in Psychological Explanations." Behavior and Philosophy 36 (January): 5-69. http://www. behavior.org/resources/206.pdf. (Pg. 4).

Fillion, Réal. 2014. "The Continuing Relevance of Speculative Philosophy of History." Journal of the Philosophy of History 8 (2): 180-195. doi:10.1163/18722636-12341270. (Pg. 2).

Flad, Rowan K. 2008. "Divination and Power: A Multiregional View of the Development of Oracle Bone Divination in Early China." Current Anthropology 49, no. 3 (June): 403-437. doi:10. 1086/588495. (Pg. 27).

Fracchia, Joseph, and R. C. Lewontin. 1999. "Does Culture Evolve?" History and Theory 38, no. 4 (December): 52-78. doi:10.1111/0018-2656.00104. (Pg. 22). 
Fredrickson, James K. 2015. "Ecological Communities by Design.” Science 348, no. 6241 (26 June): 1425-1427. doi:10.1126/science.aab0946. (Pg. 16).

Fuller, Dorian Q. 2006. "Agricultural Origins and Frontiers in South Asia: A Working Synthesis." Journal of World Prehistory 20, no. 1 (March): 1-86. doi:10.1007/s10963-006-9006-8. (Pg. 19).

Gelman, Susan A., and Cristine H. Legare. 2011. "Concepts and Folk Theories." Annual Review of Anthropology 40:379-398. doi:10.1146/annurev-anthro-081309-145822. (Pg. 3).

Gentner, Timothy Q., Kimberly M. Fenn, Daniel Margoliash, and Howard C. Nusbaum. 2006. "Recursive Syntactic Pattern Learning by Songbirds." Nature 440 (7088): 1204-1207. doi:10. 1038/nature04675. (Pg. 20).

Ghosh, Oroon K. 1964. "Some Theories of Universal History." Comparative Studies in Society and History 7, no. 1 (October): 1-20. doi:10.1017/s001041750000342x. (Pg. 2).

Gilbert, Scott F., Jan Sapp, and Alfred I. Tauber. 2012. "A Symbiotic View of Life: We Have Never Been Individuals.” The Quaterly Review of Biology 87, no. 4 (December): 325-341. doi:10.1086/668166. (Pg. 14).

Gillies, Donald. 2000. "Varieties of Propensity." British Journal for the Philosophy of Science 51 (4): 807-835. doi:10.1093/bjps/51.4.807. (Pg. 5).

Grimstead, Deanna N., and Frank E. Bayham. 2010. "Evolutionary Ecology, Elite Feasting, and the Hohokam: A Case Study from a Southern Arizona Platform Mound." American Antiquity 75, no. 4 (October): 841-864. doi:10.7183/0002-7316.75.4.841. (Pg. 20).

Hacking, Ian. 2001. An Introduction to Probability and Inductive Logic. Cambridge (GBR): Cambridge University Press. (Pg. 5).

Held, Jacob M. 2009. “Marx via Feuerbach: Species-Being Revisited.” Idealistic Studies 39 (1-3): 137-148. doi:10.5840/idstudies2009391/319. (Pg. 17).

Hochachka, P. W., and G. B. McClelland. 2014. "Cellular Metabolic Homeostasis During Largescale Change in ATP Turnover Rates in Muscles." The Journal of Experimental Biology 217:2555-2568. http://jeb.biologists.org/content/200/2/381.full.pdf. (Pg. 13).

Holzhaider, Jennifer C., Gavin R. Hunt, and Russell D. Gray. 2010. "Social Learning in New Caledonian Crows.” Learning \& Behavior 38 (3): 206-219. doi:10.3758/1b.38.3.206. (Pg. 18).

Hörz, Herbert, Hans-Dieter Pöltz, Heinrich Parthey, Ulrich Röseberg, and Karl-Friedrich Wessel. 1980. Philosophical Problems in Physical Science. 2nd ed. Studies in Marxism 7. Minneapolis, MN (USA): Marxist Educational Press. (Pg. 8).

Hovers, Erella, and Anna Belfer-Cohen. 2006. "Now You See it, Now You Don't'-Modern Human Behavior in the Middle Paleolithic." In Transitions Before the Transition: Evolution and Stability in the Middle Paleolithic and Middle Stone Age, edited by Erella Hovers and Steven L. Kuhn., 295-304. New York, NY (USA): Springer. doi:10.1007/0-387-24661-4_16. (Pp. 19, 21). 
Humphreys, Paul. 2004. "Some Thoughts on Wesley Salmon's Contributions to the Philosophy of Probability." Philosophy of Science 71, no. 5 (December): 942-949. doi:10.1086/425060. (Pg. 6).

Hunt, Gavin R., and Russell D. Gray. 2004. "The Crafting of Hook Tools by Wild New Caledonian Crows." Proceedings of the Royal Society of London B: Biological Sciences 271 (Suppl 3): S88-S90. doi:10.1098/rsbl.2003.0085. (Pg. 18).

Jacob, Eshel Ben, Israela Becker, Yoash Shapira, and Herbert Levine. 2004. "Bacterial Linguistic Communication and Social Intelligence.” TRENDS in Microbiology 12, no. 8 (August): 366372. doi:10.1016/j.tim.2004.06.006. (Pg. 16).

Jantzen, Benjamin C., Deborah G. Mayo, and Lydia Patton. 2015. "Ontology \& Methodology." Synthese 192 (11): 3413-3423. doi:10.1007/s11229-015-0972-1. (Pg. 3).

Kant, Immanuel. 1963. "Idea for a Universal History from a Cosmopolitan Point of View [1784]." In On History, edited by Lewis White Beck, 11-126. Library of Liberal Arts. Englewood Cliffs, NY (USA): Macmillan. (Pg. 1).

Killion, Thomas W. 2013. "Nonagricultural Cultivation and Social Complexity." Current Anthropology 54, no. 5 (October): 569-606. doi:10.1086/673140. (Pg. 22).

Konopka, Tomasz, Fotini Markopoulou, and Simone Severini. 2008. "Quantum Graphity: A Model of Emergent Locality.” Physical Review D 77 (10): 1-126. doi:10.1103/physrevd.77.104029. (Pg. 9).

Kosso, Peter. 1988. "Dimensions of Observability." The British Journal for the Philosophy of Science 39, no. 4 (December): 449-467. doi:10.1007/978-94-009-2434-5_3. (Pg. 9).

Krupenye, Christopher, Fumihiro Kano, Satoshi Hirata, Josep Call, and Michael Tomasello. 2016. "Great Apes Anticipate that Other Individuals Will Act According to False Beliefs." Science 354, no. 6308 (July): 110-113. doi:10.1016/j.cub.2015.08.004. (Pg. 18).

Kurby, Christopher A., and Jeffrey M. Zacks. 2008. "Segmentation in the Perception and Memory of Events." Trends in Cognitive Sciences 12 (2): 72-79. doi:10.1016/j.tics.2007.11.004. (Pg. 4).

Ladyman, James, and Don Ross. 2007. Everything Must Go: Metaphysics Naturalized. Oxford (GBR): Oxford University Press. (Pg. 4).

Laidre, Mark E. 2010. "How Rugged Individualists Enable One Another to Find Food and Shelter: Field Experiments with Tropical Hermit Crabs." Proceedings of the Royal Society B: Biological Sciences 277 (1686): 1361-1369. doi:10.1098/rspb.2009.1580. (Pg. 16).

Libet, Benjamin. 2002. "The Timing of Mental Events: Libet's Experimental Findings and Their Implications." Consciousness and Cognition 11 (2): 291-299. doi:10.1006/ccog.2002.0568. (Pg. 13).

Loew, Christian. 2016. "Causation, Physics, and Fit (forthcoming).” Synthese:1-21. doi:10.1007/ s11229-016-1029-9. (Pg. 8).

Luisi, Pier Luigi. 2007. "Chemical Aspects of Synthetic Biology." Chemistry \& Biodiversity 5 (4): 603-621. doi:10.1002/chin.200726265. (Pg. 13). 
Maiorino, Giancarlo. 1976. "Linear Perspective and Symbolic Form: Humanistic Theory and Practice in the Work of L. B. Alberti." The Journal of Aesthetics and Art Criticism 34, no. 4 (Summer): 479-486. doi:10.2307/430582. (Pg. 1).

Maldacena, Juan. 2016. "Black Holes, Wormholes and the Secrets of Quantum Spacetime." Scientific American 315, no. 5 (November): 26-31. (Pg. 8).

Marcus, Joyce, and Kent V. Flannery. 2004. "The Coevolution of Ritual and Society: New ${ }^{14} \mathrm{C}$ Dates from Ancient Mexico." Proceedings of the National Academy of Sciences of the United States of America 101, no. 52 (28 December): 18257-18261. doi:10.1073/pnas.0408551102. (Pg. 26).

Marquit, Erwin. 1988. "Contradiction as the Source of Structure and Development." In Philosophie et Culture: Actes du XVIIe congrès mondial de philosophie, edited by Venant Cauchy, 4:471475. Editions Montmorency. doi:10.5840/wcp171988498. (Pg. 11).

—. 2011. "Engels and Logical Contradictions." Originally published in Marxistiche Bl. http: //www.tc.umn.edu/ marqu002/Engels\&LContradictions.htm. (Pg. 11).

Martin, Christopher. 2003b. "On Continuous Symmetries and the Foundations of Modern Physics." Chap. 3 in Symmetries in Physics: Philosophical Reflections, edited by Katherine Brading and Elena Castellani, 29-60. Cambridge (GBR): Cambridge University Press. doi:10.1017/ cbo9780511535369.004. (Pg. 10).

Momjan, Khachik Nisanovich. 1980. Landmarks in History: The Marxist Doctrine of Socio-economic Formations. Moscow (RUS): Progress Publishers. (Pg. 24).

Moran, Dermot. 2012. Husserl's Crisis of the European Sciences and Transcendental Phenomenology: An Introduction. Cambridge (GBR): Cambridge University Press. doi:10.1017/cbo97811 39025935.003. (Pg. 1).

Morris, Brian. 1994. Anthropology of the Self: The Individual in Cultural Perspective. Anthropology, culture and society. Pluto Press. (Pg. 22).

Munro, Natalie D., and Leore Grosman. 2010. "Early Evidence (ca. 12,000 B.P.) for Feasting at a Burial Cave in Israel." Proceedings of the National Academy of Sciences of the United States of America 107, no. 35 (31 August): 15362-15366. doi:10.1073/pnas.1001809107. (Pg. 20).

Munshi, Surendra. 1978. “On Criticism in Marxist Method.” Social Scientist 6, no. 10 (May): 317. doi:10.2307/3516575. (Pg. 1).

1991. "Social Formation and the Problem of Change." Science \& Society 55, no. 2 (Summer): 175-196. http://0 - www.jstor. org. www. consuls . org/stable/pdf/10.2307/40403134.pdf. (Pg. 26).

Noffke, Nora, Kenneth A. Eriksson, Robert M. Hazen, and Edward L. Simpson. 2006. “A New Window into Early Archean Life: Microbial Mats in Earth's Oldest Siliciclastic Tidal Deposits (3.2 Ga Moodies Group, South Africa).” Geology 34, no. 4 (April): 253-256. doi:10.1130/ g22246.1. (Pg. 14). 
Norton, John D. 2003. “Causation as Folk Science.” Philosopher's Imprint 3, no. 4 (November): 1-22. http://philsci-archive.pitt.edu/1214/2/norton.rtf. (Pg. 1).

Nowack, Eva C. M., and Michael Melkonian. 2010. "Endosymbiotic Associations within Protists." Transactions of the Royal Society B: Biological Sciences 365 (1541): 699-712. doi:10.1098/ rstb.2009.0. (Pg. 15).

Nowell, April. 2010. "Defining Behavioral Modernity in the Context of Neandertal and Anatomically Modern Human Populations." Annual Review of Anthropology 39:437-452. doi:10.1146/ annurev.anthro.012809.105113. (Pg. 19).

Nyrup, Rune. 2015. "How Explanatory Reasoning Justifies Pursuit: A Peircean View of IBE." Philosophy of Science 82, no. 5 (December): 749-760. doi:10.1086/683262. (Pg. 2).

Ollman, Bertell. 2003. Dance of the Dialectic: Steps in Marx's Method. Urbana, IL (USA): University of Illinois Press. (Pg. 5).

Peoples, Hervey C., and Frank W. Marlowe. 2012. "Subsistence and the Evolution of Religion." Human Nature 23 (3): 253-269. doi:10.1007/s12110-012-9148-6. (Pg. 27).

Pitkin, Hanna Fenichel. 1987. "Rethinking Reification.” Theory and Society 16, no. 2 (March): 263-293. doi:10.1007/bf00135697. (Pg. 3).

Pohorille, Andrew. 2009. "Early Ancestors of Existing Cells." Chap. 25 in Protocells: Bridging Nonliving and Living Matter, edited by Steen Rasmussen, Mark A Bedau, Liaohai Chen, David Deamer, David C. Krakauer, Norman H. Packard, and Peter F. Stadler, 563-581. Cambridge, MA (USA): MIT Press. doi:10.7551/mitpress/9780262182683.003.0025. (Pp. 13, 14).

Popper, Karl R. 1959. "The Propensity Interpretation of Probability." The British Journal for the Philosophy of Science 10, no. 37 (May): 25-42. doi:10.1093/bjps/x.37.25. (Pg. 5).

Pronk, Raul, D. R. Wilson, and R. Harcourt. 2010. "Video Playback Demonstrates Episodic Personality in the Gloomy Octopus.” The Journal of Experimental Biology 213 (7): 1035-1041. doi:10.1242/jeb.040675. (Pg. 16).

Reiner, Richard. 1993. "Necessary Conditions and Explaining How-Possibly." The Philosophical Quarterly 43, no. 170 (January): 58-69. doi:10.2307/2219941. (Pg. 2).

Rivera, Maria C., Ravi Jain, Jonathan E. Moore, and James A. Lake. 1998. "Genomic Evidence for Two Functionally Distinct Gene Classes." Proceedings of the National Academy of Sciences 95, no. 11 (May): 6239-6244. doi:10.1073/pnas.95.11.6239. (Pg. 14).

Robus, Olin M. 2015. “Does Science License Metaphysics?” Philosophy of Science 82, no. 5 (December): 845-855. doi:10.1086/684023. (Pg. 5).

Runciman, W. G. 2005. "Stone Age Sociology." The Journal of the Royal Anthropological Institute 11, no. 1 (March): 129-142. doi:10.1111/j.1467-9655.2005.00229.xActions. (Pg. 22).

Sapp, Jan. 2009. "Transcending Darwinism: Thinking Laterally on the Tree of Life." History and Philosophy of the Llife Sciences 31 (2): 161-181. http://www.jstor.org/stable/23334441. (Pg. 14). 
Sassaman, Kenneth E. 2004. "Complex Hunter-Gatherers in Evolution and History: A North American Perspective.” Journal of Archaeological Research 12, no. 3 (September): 227-280. doi:1 0.1023/b:jare.0000040231.67149.a8. (Pg. 25).

Schiller, Friedrich von. 1972. "The Nature and Value of Universal History: An Inaugural Lecture [1789]." History and Theory 11 (3): 321-334. doi:10.2307/2504683. (Pg. 1).

Semyenov, Yu. I. 1980. "The Theory of Socio-Economic Formations and World History.” In Soviet and Western Anthropology, edited by Ernest Gellner, 29-58. London (GBR): Duckworth. (Pg. 26).

Shariff, Azim F., Ara Norenzayan, and Joseph Henrich. 2010. "The Birth of High Gods: How the cultural evolution of supernatural policing influenced the emergence of complex, cooperative human societies, paving the way for civilization." In Evolution, Culture, and the Human Mind, edited by Mark Schaller, Ara Norenzayan, Steven J. Heine, Toshio Yamagishi, and Tatsuya Kameda, 119-136. New York, NY (USA): Psychology Press. (Pg. 27).

Shettleworth, Sara J. 2009. Cognition, Evolution, and Behavior. 2nd ed. New York, NY (USA): Oxford University Press. (Pg. 18).

Shomrat, Tal, Ilaria Zarrella, Graziano Fiorito, and Binyamin Hochner. 2008. "The Octopus Vertical Lobe Modulates Short-Term Learning Rate and Uses LTP to Acquire Long-Term Memory." Current Biology 18, no. 5 (11 March): 337-342. doi:10.1016/j.cub.2008.01.056. (Pg. 16).

Simard, Suzanne, Amanda Asay, Kevin Beiler, Marcus Bingham, Julie Deslippe, Xinhua He, Leanne Philip, Yuanyuan Song, and François Teste. 2015. "Resource Transfer Between Plants Through Ectomycorrhizal Fungal Networks." In Mycorrhizal Networks. Dordrecht (NED): Springer. doi:10.1007/978-94-017-7395-9_5.(Pg. 20).

Singer, Merrill. 1996. "Farewell to Adaptationism: Unnatural Selection and the Politics of Biology." Medical Anthropology Quarterly N.S. 10, no. 4 (December): 496-515. doi:10.1525/maq. 1996.10.4.02a00050. (Pg. 13).

Smeenk, Chris. 2006. “The Elusive Higgs Mechanism.” Philosophy of Science 73, no. 5 (December): 487-499. (Pg. 7).

Sneed, Annie. 2015. "The Origin of Power: A New Hypothesis about the Debut of Mitochondria." Scientific American 312, no. 2 (February): 20-21. doi:10.1038/scientificamerican0215-20. (Pg. 15).

Soare, Robert I. 1996. "Computability and Recursion.” The Bulletin of Symbolic Logic 2, no. 3 (September): 284-321. doi:10.2307/420992. (Pg. 16).

Sperber, Dan, and Nicolas Claidière. 2006. "Why Modeling Cultural Evolution Is Still Such a Challenge.” Biological Theory 1 (1): 20-23. doi:10.1162/biot.2006.1.1.20. (Pg. 22).

Sterpetti, Fabio. 2015. "Scientific Realism, Adaptationism and the Problem of the Criterion." Kairos. Journal of Philosophy and Science 13:7-45. http://philpapers .org/rec/STESRA - 12. (Pg. 4). 
Tennie, Claudio, Josep Call, and Michael Tomasello. 2009. "Ratcheting up the Ratchet: On the Evolution of Cumulative Culture." Philosophical Transactions of the Royal Society: Biological Sciences 364, no. 1528 (August): 2405-2415. doi:10.1098/rstb.2009.0052. (Pg. 22).

Testart, Alain. 1989. “Aboriginal Social Inequality and Reciprocity.” Oceania 60, no. 1 (September): 1-16. doi:10.1002/j.1834-4461.1989.tb00348.x. (Pg. 22).

Tierney, Brian. 2006. "Dominion of Self and Natural Rights before Locke and after." In Transformations in Medieval and Early-Modern Rights Discourse, edited by Virpi Makinen and Petter Korkman, 173-203. The New Synthese Historical Library, 59. New Yori, NY (USA): Springer-Verlag. (Pg. 1).

Tollefson, Kenneth D. 1995. "Potlatching and Political Organization among the Northwest Coast Indians.” Ethnology 34, no. 1 (Winter): 53-73. doi:10.2307/3773863. (Pg. 20).

Velleman, J. David. 2003. "Narrative Explanation.” The Philosophical Review 112, no. 1 (January): 1-25. doi:10.1215/00318108-112-1-1. (Pg. 6).

Wade, Lizzie. 2016. "Neanderthals Made Jewelry, Proteins Confirm.” Science 353, no. 6306 (23 September): 1350. (Pg. 17).

Waters, Christopher M., and Bonnie L. Bassler. 2005. "Quorum Sensing: Cell-to-Cell Communication in Bacteria." The Annual Review of Cell and Developmental Biology 21:319-346. doi:10.1146/annurev.cellbio.21.012704.131001. (Pg. 15).

Wilson, Jessica M. 2012. "Fundamental Determinables.” Philosopher's Imprint 12, no. 4 (February): 1-17. http://philpapers.org/rec/WILFD. (Pg. 3).

Zak, Paul J., Angela A. Stanton, and Sheila Ahmadi. 2007. "Oxytocin Increases Generosity in Humans.” PLoS One 2 (11). doi:10.1371/journal.pone.0001128. http://dx.plos.org/10.1371/journal. pone.0001128;jsessi. (Pg. 21).

Zimmer, Carl. 2008. “How Smart Is the Octopus?” Slate Magazine (23 June). http://www.slate.com/ articles/health_and_science/science/2008/06/how_smart_is_the_octopus.html. (Pg. 18). 